\title{
Impacts of epidemic outbreaks on supply chains: mapping a research agenda amid the COVID-19 pandemic through a structured literature review
}

\author{
Maciel M. Queiroz ${ }^{1}$ (D) Dmitry Ivanov ${ }^{2}$ (D) Alexandre Dolgui $^{3}$ (D) \\ Samuel Fosso Wamba ${ }^{4}$ (D)
}

Published online: 16 June 2020

(c) The Author(s) 2020

\begin{abstract}
The coronavirus (COVID-19) outbreak shows that pandemics and epidemics can seriously wreak havoc on supply chains (SC) around the globe. Humanitarian logistics literature has extensively studied epidemic impacts; however, there exists a research gap in understanding of pandemic impacts in commercial SCs. To progress in this direction, we present a systematic analysis of the impacts of epidemic outbreaks on SCs guided by a structured literature review that collated a unique set of publications. The literature review findings suggest that influenza was the most visible epidemic outbreak reported, and that optimization of resource allocation and distribution emerged as the most popular topic. The streamlining of the literature helps us to reveal several new research tensions and novel categorizations/ classifications. Most centrally, we propose a framework for operations and supply chain management at the times of COVID-19 pandemic spanning six perspectives, i.e., adaptation, digitalization, preparedness, recovery, ripple effect, and sustainability. Utilizing the outcomes of our analysis, we tease out a series of open research questions that would not be observed otherwise. Our study also emphasizes the need and offers directions to advance the literature on the impacts of the epidemic outbreaks on SCs framing a research agenda for scholars and practitioners working on this emerging research stream.
\end{abstract}

Keywords Supply chain · COVID-19 · Influenza · Resilience · Epidemic outbreaks · Pandemic $\cdot$ Structured literature review $\cdot$ Adaptation $\cdot$ Digitalization $\cdot$ Preparedness $\cdot$ Recovery $\cdot$ Ripple effect $\cdot$ Sustainability

Dmitry Ivanov

divanov@hwr-berlin.de

Extended author information available on the last page of the article 


\section{Introduction}

The contemporary world has been challenged by unprecedented disease outbreaks (Chew et al. 2004; Lin et al. 2020; Nigmatulina and Larson 2009), whith significant negatively effects on the society as a whole, but also on the efficiency of operations and supply chain (SC) management (OSCM) business models. Such disruptive impacts frequently yield the ripple effects (Ivanov 2020a; Ivanov et al. 2018; Pavlov et al. 2019b). While SCs across the globe have been already suffering from epidemics and pandemic, they have recently been seriously hit by an unprecedented, far-reaching disruptive epidemic outbreak, namely COVID-19 (Boccaletti et al. 2020), which is considered as a new type of extremely contagious coronavirus, with destructive impacts (Choi 2020; Ivanov 2020a; Ivanov and Dolgui 2020b).

The COVID-19 was first reported in Wuhan, Hubei province, China, in the late 2019. As noted by the Johns Hopkins University on May 27, 2020, the number of confirmed cases reported around the world have been steadily growing, reaching 5.69 millions with 355,575 deaths (Johns Hopkins University \& Medicine 2020). In view of this exponential growth, the COVID-19 was declared a world pandemic by the World Health Organization-WHO (2020) on March 11.

The impacts of the COVID-19 on SCs have already gained attention of scholars (Choi 2020; Govindan et al. 2020; International Journal of Production Research 2020a, 2020b; Journal of Operations Management 2020; Ivanov 2020a; Lin et al. 2020; Sarkis et al. 2020) and industry experts (Business Insider 2020; Deloitte 2020; Forbes 2020a, b; Fortune 2020; Harvard Business Review 2020; Institute for Supply Chain Management-ISM 2020). The COVID-19 epidemic is already impacting the OSCM at a large scale (Lin et al. 2020). Fortune (2020), in a report published on 21 February 2020, indicated that $94 \%$ of the companies listed in the Fortune 1000 list were facing SC disruptions due to the COVID-19. As for Deloitte (2020), the publication highlighted that the whole effect of the pandemic on SCs remained uncharted. The past epidemic outbreaks offer valuable lessons in relation to the SCs. The World Economic Forum-WEF (2020a, b) emphasized the need for firms and organizations to reengineer and adapt SCs to their future trade challenges. For instance, the short-term priority may be 'transport and production' and 'worker movement', while in the long term, capabilities and strategies related to 'digital readiness \& data sharing' would be developed and implemented for SCs (World Economic Forum-WEF 2020a, b).

In a context where severe disruptions (e.g., manufacturers closed or partially closed, airports operating with harsh restrictions, shortages of medical equipment and supplies) are recorded in the global SCs (Ivanov 2020a; McKinsey \& Company 2020; World Economic Forum-WEF 2020a), a good number of industries (automotive, electronics, medical equipment, consumer goods, etc.) also experience ripple effects (Dolgui et al. 2018; Ivanov $2020 \mathrm{a}, \mathrm{b})$. For example, as China is considered a world's factory, the pandemic's disruptions to SCs around the world started there before spreading elsewhere (Deloitte 2020). The severe ripple effects from this challenge requires different strategies and actions, including robust SC resilience strategies (Chen et al. 2019; Ivanov and Sokolov 2019; Pournader et al. 2020). Moreover, responses from the OSCM to such outbreaks by should consist in rendering global SCs more integrated and digitally ready (Choi et al. 2020; World Economic Forum-WEF 2020a, b). The digitalization of the SCs could improve the quality of the response to outbreak-related disruptions by enhancing the OSCM flexibility (Ivanov et al. 2019) in such circumstances. 
It should be noted that the OSCM literature has approached studies on different types of epidemic outbreaks, with various objectives. For instance, outbreaks of influenza (Mamani et al. 2013), Ebola (Büyüktahtakın et al. 2018), Cholera (Anparasan and Lejeune 2017) and malaria (Parvin et al. 2018), among others, have been thoroughly studied. The majority of these papers have devoted particular attention to resource allocation, distribution of the medicaments, vaccines procurement policies, and emergency health response. It is true that recent advances have been made by the literature concerning SC response (Aldrighetti et al. 2019; Banomyong et al. 2019; Lu et al. 2017; Song et al. 2018; Shen and Li 2017) and epidemic outbreaks operations (Anparasan and Lejeune 2019; Chick et al. 2008; Long et al. 2018; Paul and Venkateswaran 2020), but the effects of epidemic outbreaks on SCs (Ivanov 2020a; Sarkis et al. 2020) are still to be adequately investigated. In this regard, operations research (OR) and operations management (OM) approaches such as network and complexity theories (e.g., Bayesian networks, Markov chains, network theory, ecological modeling) (Demirel et al. 2019; Hosseini and Ivanov 2019; Li and Zobel 2020), simulation (agent-based simulation, discrete-event simulation, systems dynamics) (Ghadge et al. 2013; Zhao et al. 2019; Ivanov 2020a), optimization (stochastic programming, robust optimization, mixed-integer linear programming, heuristics, dynamic programming) (Yoon et al. 2018; Amiri-Aref et al. 2019; Sawik 2019) could bring interesting insights to address this complex pandemic context. Moreover, empirical theories such resources based view (RBV), dynamic capabilities, contingency theory, organizational information processing theory (OIPT) with applications to resilience (Bode et al. 2011; Dubey et al. 2019b, c, 2020) could be employed jointly with OR/OM approaches to frame empirically-grounded analytics and to examine the impacts of epidemic outbreaks on SCs.

However, the literature reporting the application areas of these methods in a systematic way remains scarce. The results remain scattered across different sources and rather unsystemized. We could identify only one paper covering the literature review on the impacts of epidemic outbreaks on logistics (Dasaklis et al. 2012). Considering the paucity of the literature on the effects of epidemic outbreaks on SCs (Ivanov 2020a; Ivanov and Dolgui 2020b), our study intends to unlock and shed more light in this discussion, providing valuable insights that will enable decision-makers and policy-makers to develop their response plans for SCs. In contrast to Dasaklis et al. (2012), our study analyses the latest articles published by March 2020 and offers a broader picture by covering different areas of OSCM. Moreover, our ultimate objective goes beyond a pure literature review to identify what happended in the past, but we rather use the literature review results to project future research agenda for OSCM under the conditions of COVID-19 pandemic.

For the moment, this topic is still at a nascent stage, even though it is promising and crucial research area (Haren and Simchi-Levi 2020; Ivanov 2020a; World Economic Forum-WEF 2020a, b). Therefore, this work aims to help bridge the gap by investigating the available OSCM literature on the impact of epidemic outbreaks on SCs and logistics while proposing avenues for improvements. We seek to provide a robust research agenda that will contribute to advancing the extant relevant literature, feeding decision- and policy-makers with significant insights for the OSCM-related fields. Once again, the extant literature remains silent on the disruptive impacts of epidemic outbreaks on SCs, and this study is committed to help bridging this gap. More specifically, we are taking the lead of research by attempting to answer the following research questions (RQs).

RQ1: How does the OSCM literature address issues related to epidemic outbreaks in terms of their impact on logistics and SCs? 
RQ2: What are the main problem settings and methods used?

RQ3: What are the open questions and future research opportunities framing OSCM at the times of COVID-19 pandemic?

The following contributions are expected from this study. The first and main contribution of our study is to map out an emergent research agenda for OSCM at the times of COVID-19 pandemic. The second contribution is a systematization of the literature investigating the interplay between epidemic outbreaks and SCs. The third contribution is an identification of several open research questions to be explored in very near future.

In terms of organization, Sect. 2 of this paper highlights the SLR methodology, supported by its findings and the content analysis in Sect. 3. Section 4 elaborates on a research agenda for OSCM at the times of COVID-19 pandemic. Section 5 serves as a conclusion and underscores other key considerations.

\section{Systematic literature review}

Systematic literature review (SLR) has a long tradition, mainly in medical sciences (Cochrane Library 2018). The SLR is briefly defined as: "[...] an efficient technique for hypothesis testing, for summarising the results of existing studies, and for assessing consistency among previous studies; these tasks are clearly not unique to medicine." (Petticrew 2001, pp. 99-100).

The SLR has been recently used successfully in the SC context (Mustafa Kamal and Irani 2014; Queiroz et al. 2019b; Roberta Pereira et al. 2014; Tachizawa and Wong 2014), which is eloquent evidence that, due to its systematic approach, the SLR is considered a rigorous method to conduct literature reviews. At the first stage of our approach, we therefore started with defining the scope and delimitating the subjects (Tranfield et al. 2003), taking into account their interdisciplinary nature. For the sake of objectivity and reliability in the whole process, we designed a research protocol (Table 1) (Tranfield et al. 2003).

At the second stage, we performed the search to identify the relevant papers. Following the recommendations (Tranfield et al. 2003), we considered only documents that met the full research protocol criteria. To comply with internal validity, we retained only journals indexed by Scopus. Moreover, to extract data and explore the papers, we used the quantitative software MAXQDA (Queiroz et al. 2019b; Schanes et al. 2018), and the Bibliometrix, an R-tool for science mapping and analysis (Aria and Cuccurullo 2017). At the third and last stage of the SLR, we reported the main findings from the analysis of papers. This led to unveiling several insights into both the knowledge literature and a number of research topics (Tranfield et al. 2003). Figure 1 highlights the main schematical flow of the review process.

Remark 1 We note that our search was specifically designed in light of two aspects, i.e. (i) focus on commercial SCs and logistics (and not on humanitarian logistics) and (ii) focus on the evident and tangible logistics, production and SC contexts (i.e., it shoud be evident from the paper that it explicitly deals with an epidemic and SC issues; for example the papers that just mention epidemics as a possible risk were not considered). 
Table 1 Research protocol

\begin{tabular}{|c|c|}
\hline Research protocol & Details description \\
\hline Research databases: & $\begin{array}{l}\text { Scopus Database, ScienceDirect (Elsevier), Emeral- } \\
\text { dinsight (Emerald), Wiley Online Library (Wiley), } \\
\text { Taylor \& Francis Online (Taylor \& Francis), } \\
\text { Springer Link (Springer), Inderscience, and Informs } \\
\text { PubsOnline }\end{array}$ \\
\hline Publication type: & Peer-review journals (indexed by Scopus) \\
\hline Language: & We considered only papers written in English \\
\hline Date range: & $\begin{array}{l}\text { The range period for consideration was 2003-2020 } \\
\text { (March 22) }\end{array}$ \\
\hline Search fields: & Titles, abstracts, and keywords \\
\hline $\begin{array}{l}\text { Search terms: applied in Titles in Scopus Database } \\
\text { and in Titles, Abstracts, and Keywords in the } \\
\text { other databases }\end{array}$ & $\begin{array}{l}\text { (“outbreak*" OR "pandemic*” OR "epidemic*" } \\
\text { OR "disease*" AND "humanitarian operati*" OR } \\
\text { "humanitarian relief*" OR "suppl* Chain*” OR } \\
\text { "logistic*") }\end{array}$ \\
\hline Criteria for inclusion & $\begin{array}{l}\text { Papers that presented some outbreak in a logistics/ } \\
\text { SC context }\end{array}$ \\
\hline Criteria for exclusion & $\begin{array}{l}\text { Papers that presented outbreak discussion purely } \\
\text { without protagonism of the logistics/SC, and review } \\
\text { papers }\end{array}$ \\
\hline Data extraction & $\begin{array}{l}\text { We used an R-tool software Bibliometrix and the } \\
\text { qualitative software MAXQDA }\end{array}$ \\
\hline Data analysis and synthesis & $\begin{array}{l}\text { Supported by the Bibliometrix and MAXQDA, we } \\
\text { performed a content analysis approach }\end{array}$ \\
\hline
\end{tabular}

*Remark 2 In this query, due to the search considered title, abstract and keywords, we preselected only the first potential papers that met the Remark 1. Besides, forthcoming papers were also considered.

\section{Findings from the literature review}

\subsection{Basic informations from the papers selected}

As signalized in the previous section, we used an R-tool software application called Bibliometrix (Aria and Cuccurullo 2017; Zhou et al. 2019). The Bibliometrix is open-source application that has the potential to import data from different sources (Scopus, Clarivate Analytics' Web of Science, among others). It has been used successfully in various literature review works (Bernardet et al. 2019; Demiroz and Haase 2019; Purba et al. 2019; Zhou et al. 2019), providing support for robustness and reliability in science mapping. Although we initially used the year 2003 in our searches, the first paper that met our research protocol dates back to 2008. However, with 12 years of time horizon, only 32 documents were selected considering all the inclusion criteria. 


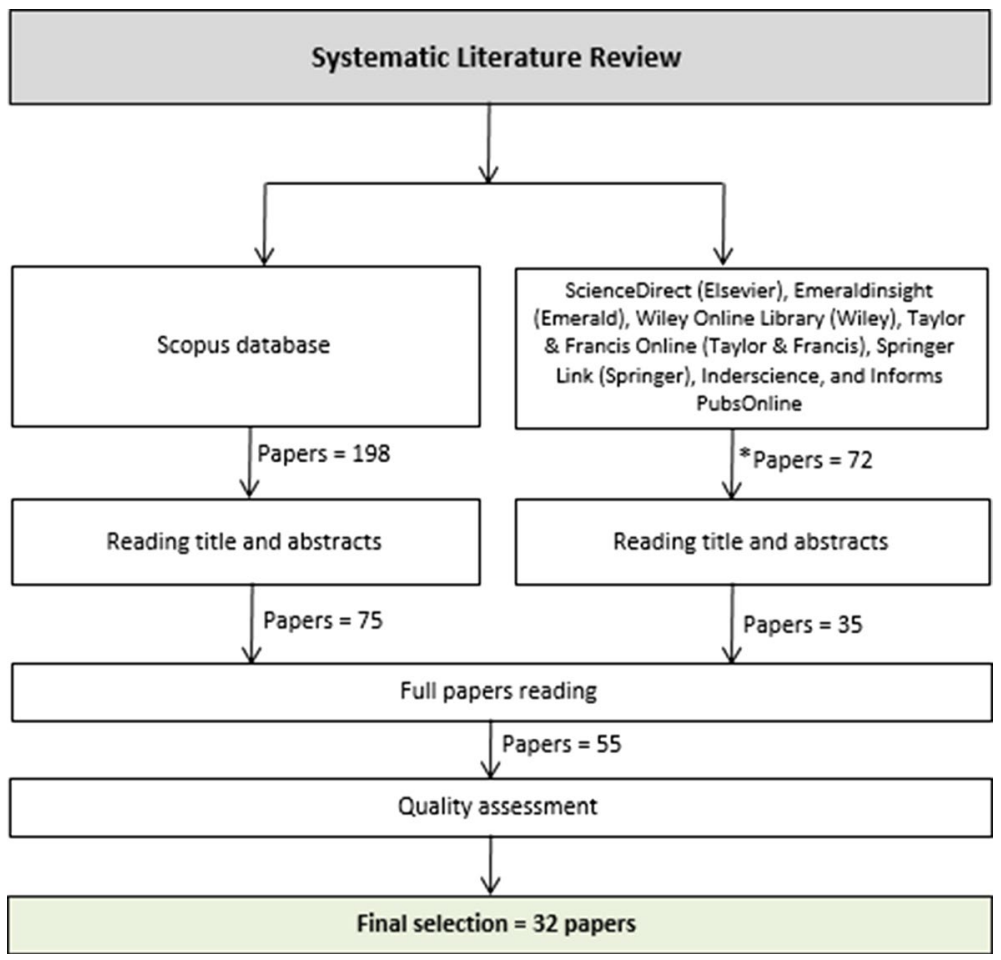

Fig. 1 Research protocol to the SLR

\subsection{Publications by journals}

Table 2 shows the number of papers published in the course of each journal. The journals devoted to operations research (OR) topped the chart. Moreover, OR, operations management (OM) and logistics journals represent the majority of publications. They include publications such as Manufacturing and Service Operations Management, Journal of Humanitarian Logistics and Supply Chain Management, Production and Operations Management, Transportation Research Part E, among others. However, there are also influential medical/interdisciplinary journals such as the case of Lancet and CHEST.

Moreover, our SLR identified the protagonism of the OR/OM journals while discovering that the number of papers on epidemic outbreaks was very limited. In the same light, journals dedicated to logistics and SCs were also in small number. Therefore, it becomes necessary to bridge this gap by producing more studies on the epidemic issues, including the COVID-19.

The top journals with regular papers published on these topics are European Journal of Operational Research (EJOR), Annals of Operations Research (ANOR), Journal of the Operational Research Society (JORS), and Manufacturing and Service Operations Management (M\&SOM). These journals accounted for $34.38 \%$ of the publications. Concerning the different behaviors of these journals over time, it appears that 
Table 2 Articles published by the journal

\begin{tabular}{ll}
\hline Sources & Articles \\
\hline European Journal of Operational Research & 4 \\
Annals of Operations Research & 3 \\
Journal of the Operational Research Society & 2 \\
Manufacturing and Service Operations Management & 2 \\
American Journal of Medicine & 1 \\
CHEST & 1 \\
Computers and Industrial Engineering & 1 \\
Computers and Operations Research & 1 \\
Influenza and Other Respiratory Viruses & 1 \\
International Journal of Integrated Supply Management & 1 \\
International Journal of Mathematics in Operational Research & 1 \\
International Journal of Production Research & 1 \\
International Journal of Systems Science: Operations and Logistics & 1 \\
Journal of Applied Poultry Research & 1 \\
Journal of Emergency Management & 1 \\
Journal of Humanitarian Logistics and Supply Chain Management & 1 \\
Management Science & 1 \\
Networks and Spatial Economics & 1 \\
Operations Research & 1 \\
PLOS Computational Biology & 1 \\
Production and Operations Management & 1 \\
Promet - Traffic - Traffico & 1 \\
Socio-Economic Planning Sciences & 1 \\
The Lancet & 1 \\
\hline
\end{tabular}

the EJOR leads in terms of output, while the ANOR makes proof of a steady engagement, with one yearly publication over the last 3 years. It is noteworthy highlighting the recent interest for production research, SC and logistics by some dedicated journals, such as the International Journal of Production Research, the International Journal of Integrated Supply Management and Transportation Research Part E (with one paper in 2020* until March 18).

\subsection{Word TreeMap dynamics}

Figure 2 displays a Word TreeMap dynamics, based on keywords plus. It means that these words were not necessary given by the authors; instead, these were acquired from the titles of references from our dataset (32 papers). In addition, the frequency of the keywords determines the size of the rectangles, while the colors emphasize the relationship with the keyword. The role of word segments such as "epidemic outbreak," "humanitarian logistics", "influenza", "optimization", "resource allocation" and "supply chain" is quite identifiable. In the other rectangles (smaller sizes), we have various related words, but also emerging topics that are being already highlighted, such as "COVID 19", "coronavirus", "decentralized logistics systems", "digital twin", and "data-driven models." 


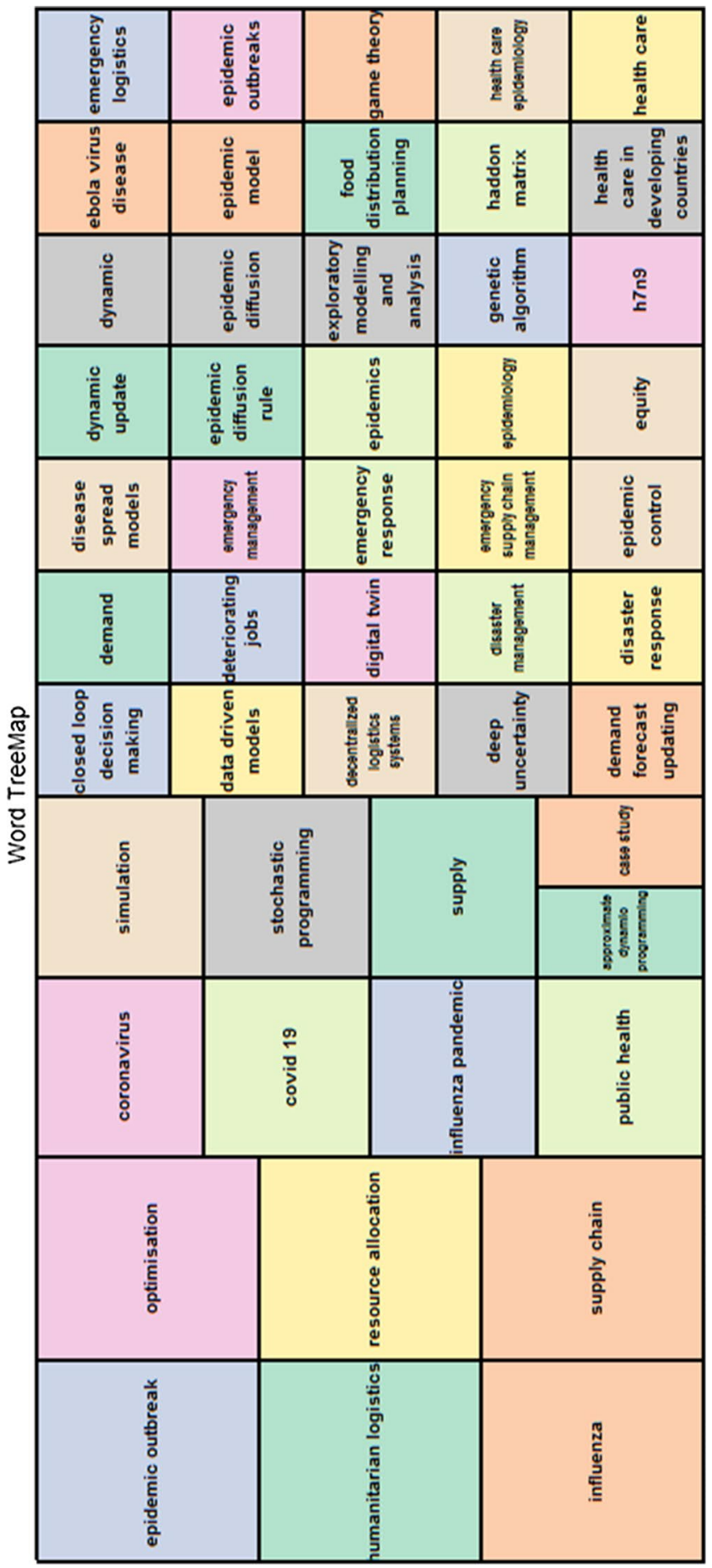

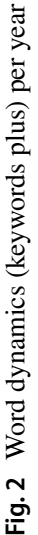


Moreover, there is a tendency for Coronavirus and COVID-19 to outperform each other over time, but we can also notice the growth of other interesting topics related to "Coronavirus and COVID-19", such as "optimisation", "epidemic outbreak", humanitarian logistics" and "resource allocation". In the other rectangles (smaller sizes) we have various related words.

Other related emerging topics can be unveiled using words and groups of words such as "COVID-19", "coronavirus", "decentralized logistics systems", "digital twin", and "data-driven models". Taking into account the word dynamics, we can see that "emergency response" is a well-explored topic due to its variations (e.g., disaster response, disaster management, emergency management, emergency SC management, and emergency logistics). Therefore, with regard to our research questions and objectives, it clearly appears that related impact themes as indicated through the words 'risks' and 'resilience' (the most frequent words) are scarse. Therefore, our study advocates the use of these two words in order to see through the literature and investigate more deeply the impact of epidemic outbreaks on SCs.

\subsection{Multiple correspondence analysis}

In Fig. 3, we point out the conceptual structure map by employing a multiple correspondence analysis (MCA) method. The MCA is a data reduction technique that builds a map of the scientific conceptual structure (Aria and Cuccurullo 2017). Thus, in summary, the MCA plots a robust two-dimensional graphical map while taking into account the similarities of the distribution of the words used in its representation (Aria and Cuccurullo 2017; Cuccurullo et al. 2016). The more such words are similar and closer in the map, the better they will be represented.

In this regard, a concentration of optimization techniques is essential to provide an adequate response to epidemic outbreaks (e.g., optimization, Markov decision processes,

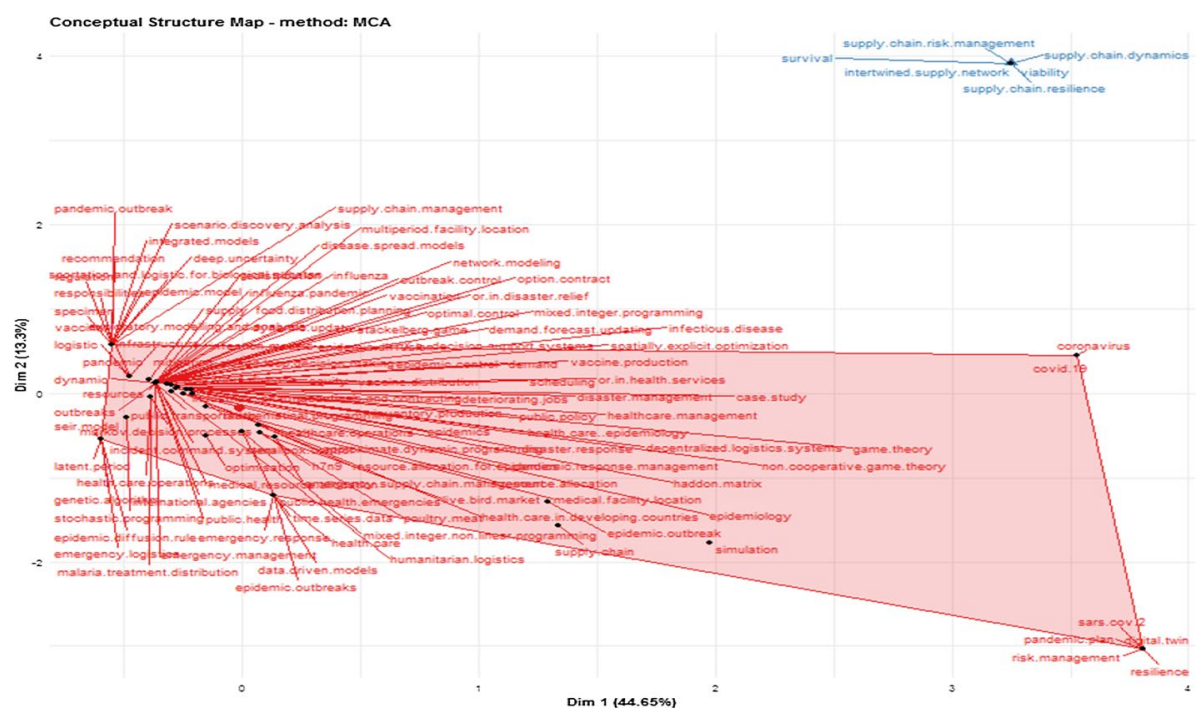

Fig. 3 Conceptual structure map 
stochastic programming, health care operations, mixed integer and non-linear programming, explicit optimization). Another interesting concentration is related to the susceptible exposed infectious removed (SEIR) model, epidemic diffusion rule, genetic algorithm, and latent period.

Also, the efforts related to epidemic response are represented by a significant concentration of "pandemic response management", "emergency OSCM", "public health emergencies", "healthcare management", "resource allocation", and "vaccine distribution", inter alia. Besides, there are other interesting concentrations related to "network modeling", "transportation", "demand forecast", "data-driven models", and "options contract". Finally, blue words represent an emerging, challenging and unexplored topic (Ivanov 2020a, b) related to the COVID-19 pandemic. In this landscape, important words appear in this concentration, like "resilience", "digital twin", "risk management", and "pandemic plan".

\subsection{Categorization of epidemic and outbreaks in SCM}

To synthesize our main findings from the literature review, we employed a content analysis technique (Kache and Seuring 2014; Queiroz et al. 2019b; Brandenburg and Rebs 2015) that could provide validity, objectivity and reliability through a coding-scheme approach, as recommended by previous studies (Queiroz et al. 2019b; Spens and Kovács 2006). The categories considered during the analysis of papers were Outbreak/Disease reported, Purpose, Main method/Theoretical approach, and Supply chain/Logistics/Operations implications. Table 3 highlights the findings from the content analysis.

\subsection{Discussion of findings}

The categorization of the selected papers by the content analysis unlocked exciting findings. Firstly, we identified that the majority of papers were devoted to the Influenza epidemic outbreak (43.75\%), followed by papers without any particular focus on a specific epidemic/outbreak, but with some insights into epidemic/outbreak control (18.75\%). Then, Cholera and Ebola held the third and fourth rank (12.5\%), followed by COVID-19 (9.38\%), Malaria, and Smallpox, with one paper dedicated to these epidemics.

Furthermore, the selected papers mostly presented optimization models for resource allocations (medicaments and vaccines distribution, vaccines procurement contracts, patient allocation, facilities location, etc.). However, some studies approached these epidemic outbreaks for other purposes. This is the case of Bogoch et al. (2015), which considered the impact of Ebola diffusion on international air travelers and on the logistics infrastructure network that is required to minimize the spread. It is also the case of a paper by Ivanov (2020a, b) that addressed the COVID-19 impacts on SCs and how to predict it by employing simulation techniques (Ivanov 2020a; Ivanov and Das 2020; Ivanov and Dolgui 2020b).

Regarding the "Main Method/Theoretical Approach" reported by the papers, it should be recalled that most papers were related to optimization models, and therefore, they used different mathematical models and approaches. They included mixed integer programming (Liu and Zhang 2016; Büyüktahtakın et al. 2018), linear programming (Dasaklis et al. 2017), game theory (Shamsi et al. 2018; Chick et al. 2008), case study and simulation (Ivanov 2020a, b), case study and SIR model (Rachaniotis et al. 2012), case study and stochastic programming/Markov (Parvin et al. 2018), among others. Table 4 shows the distribution of papers by type of epidemic outbreak. 


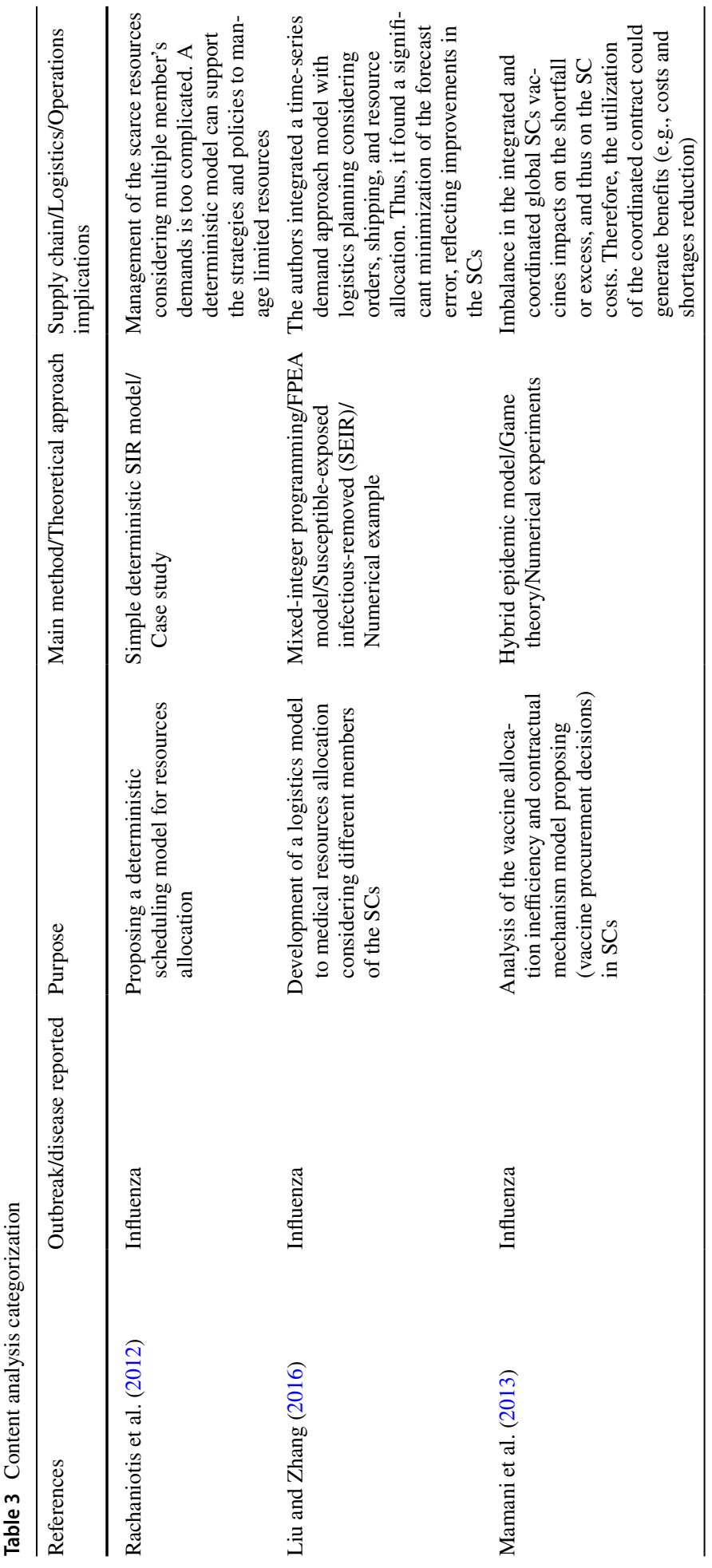




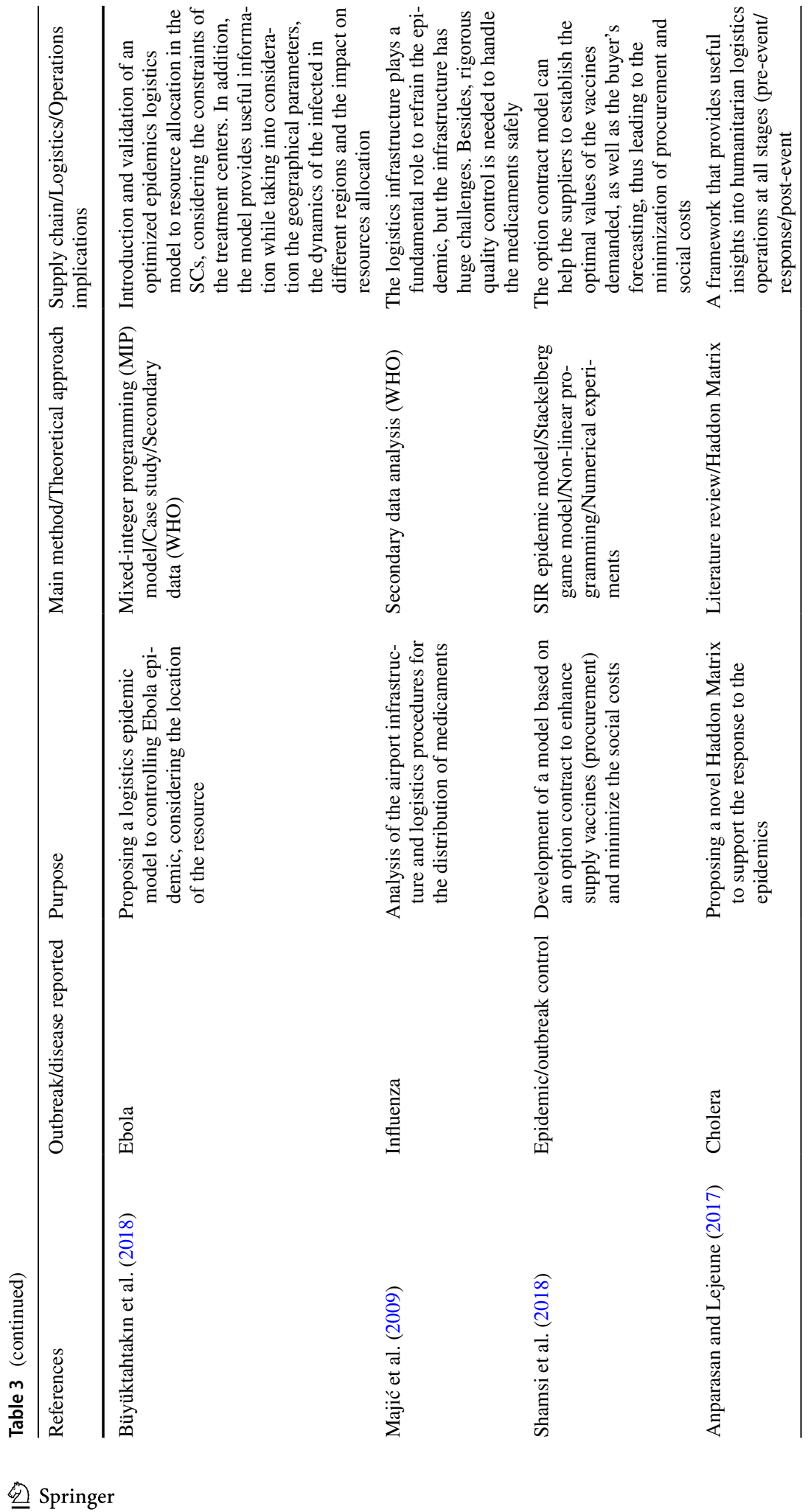




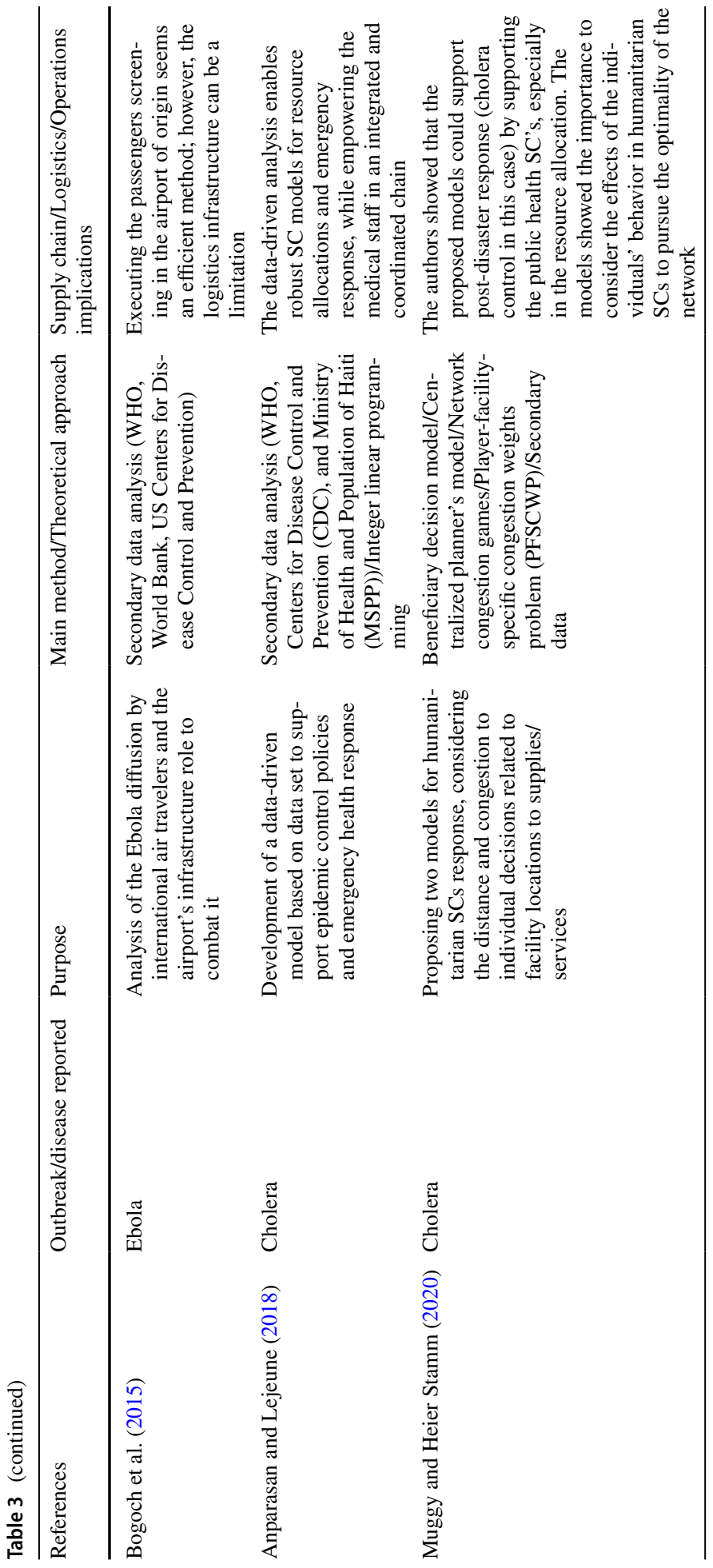




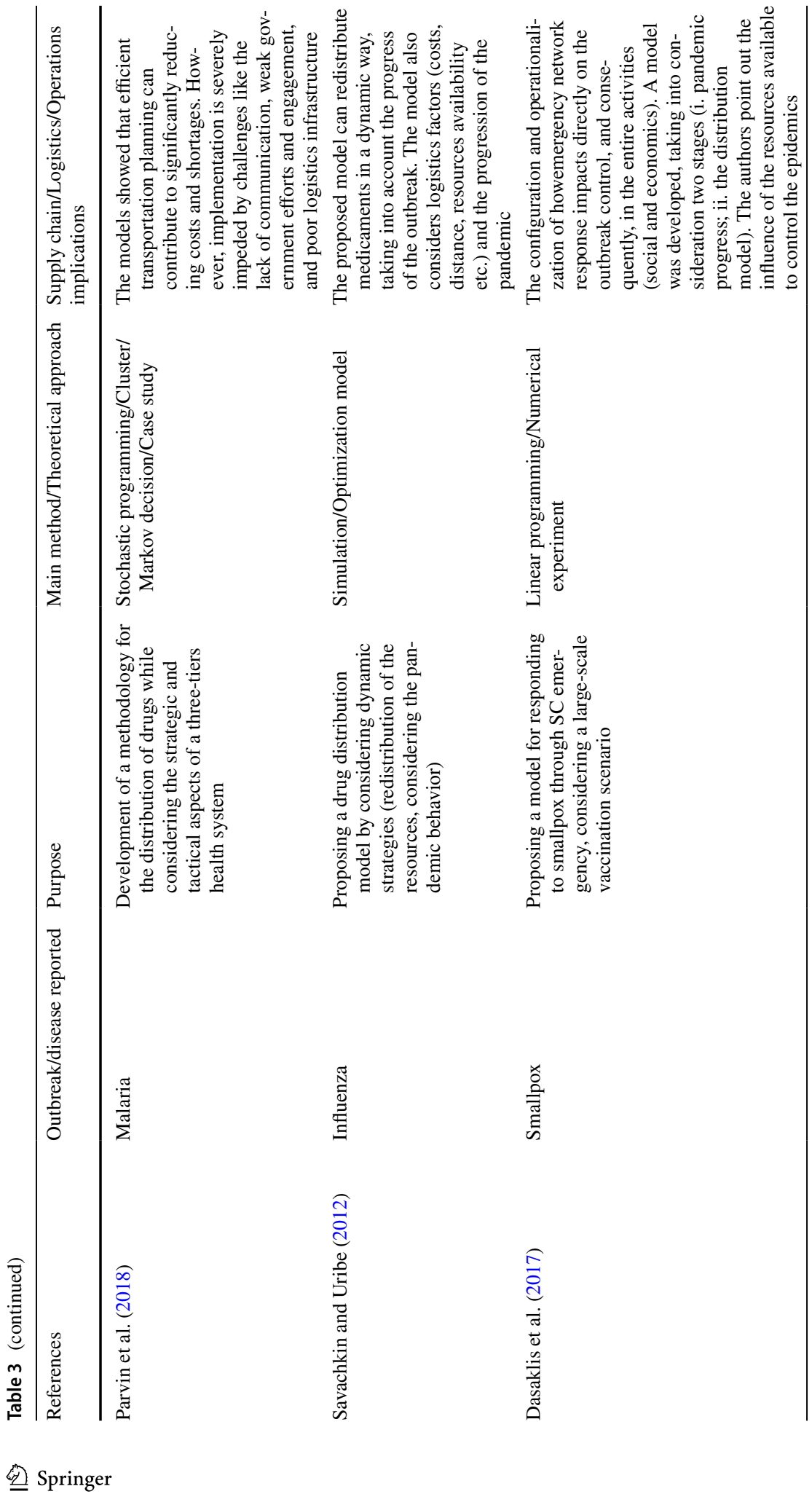




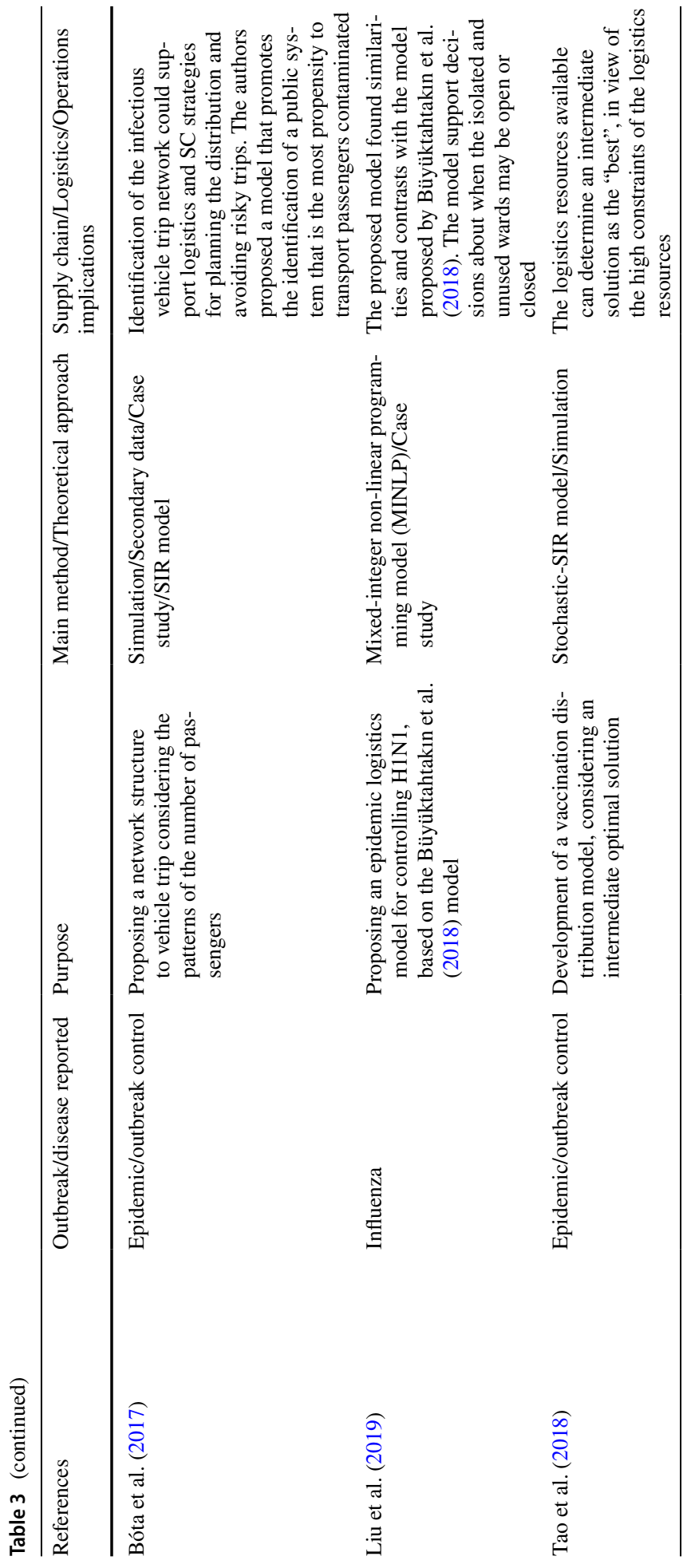




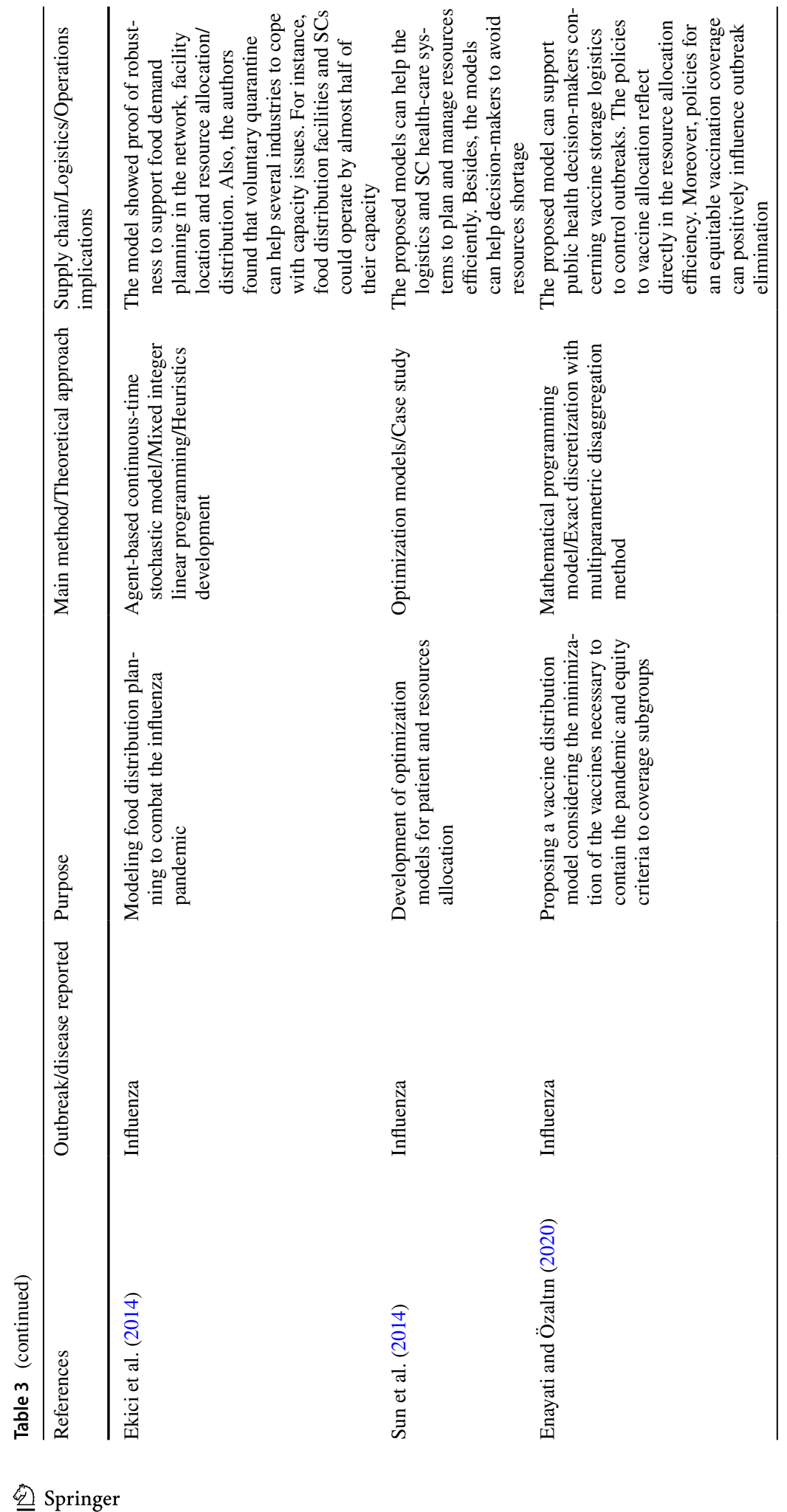




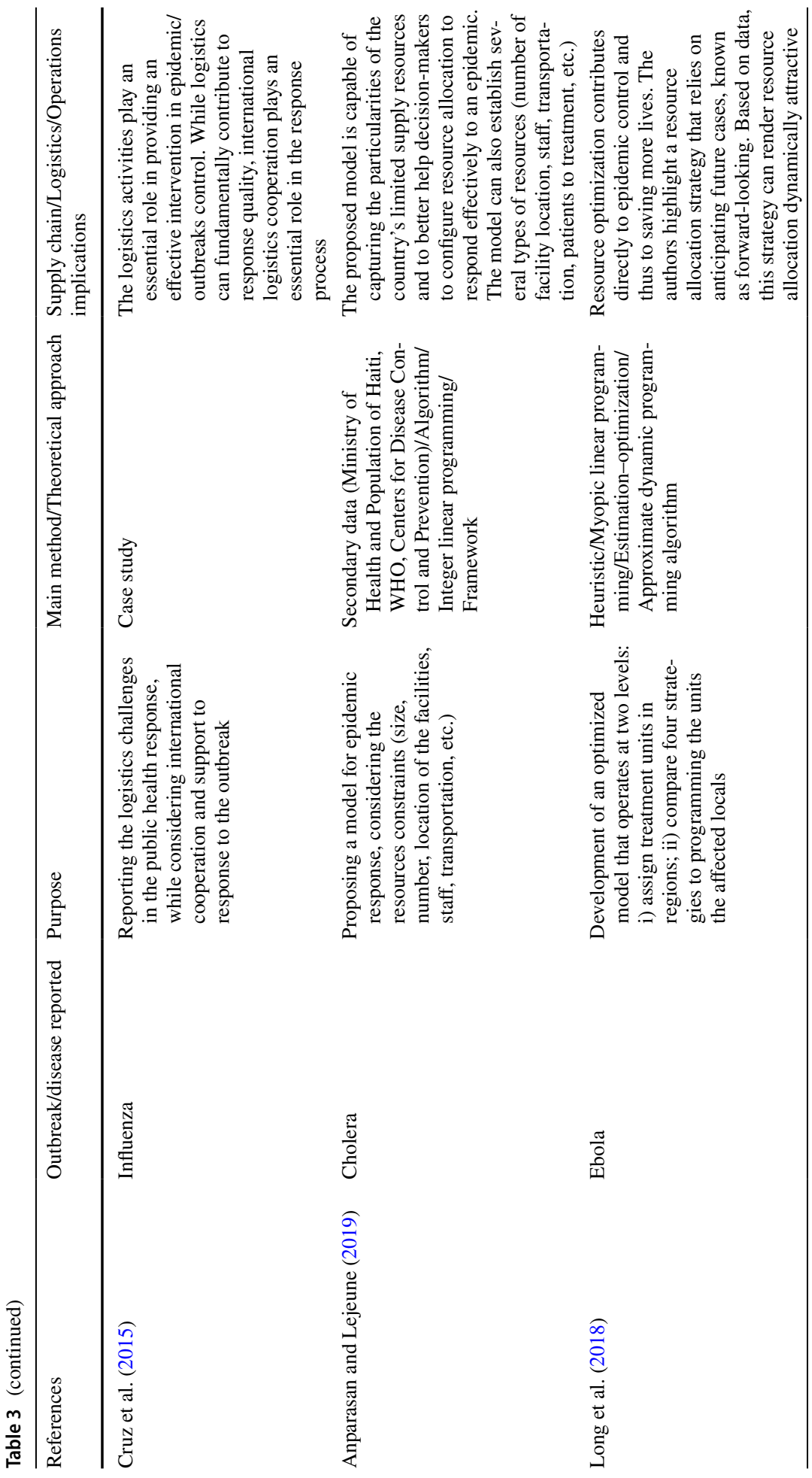




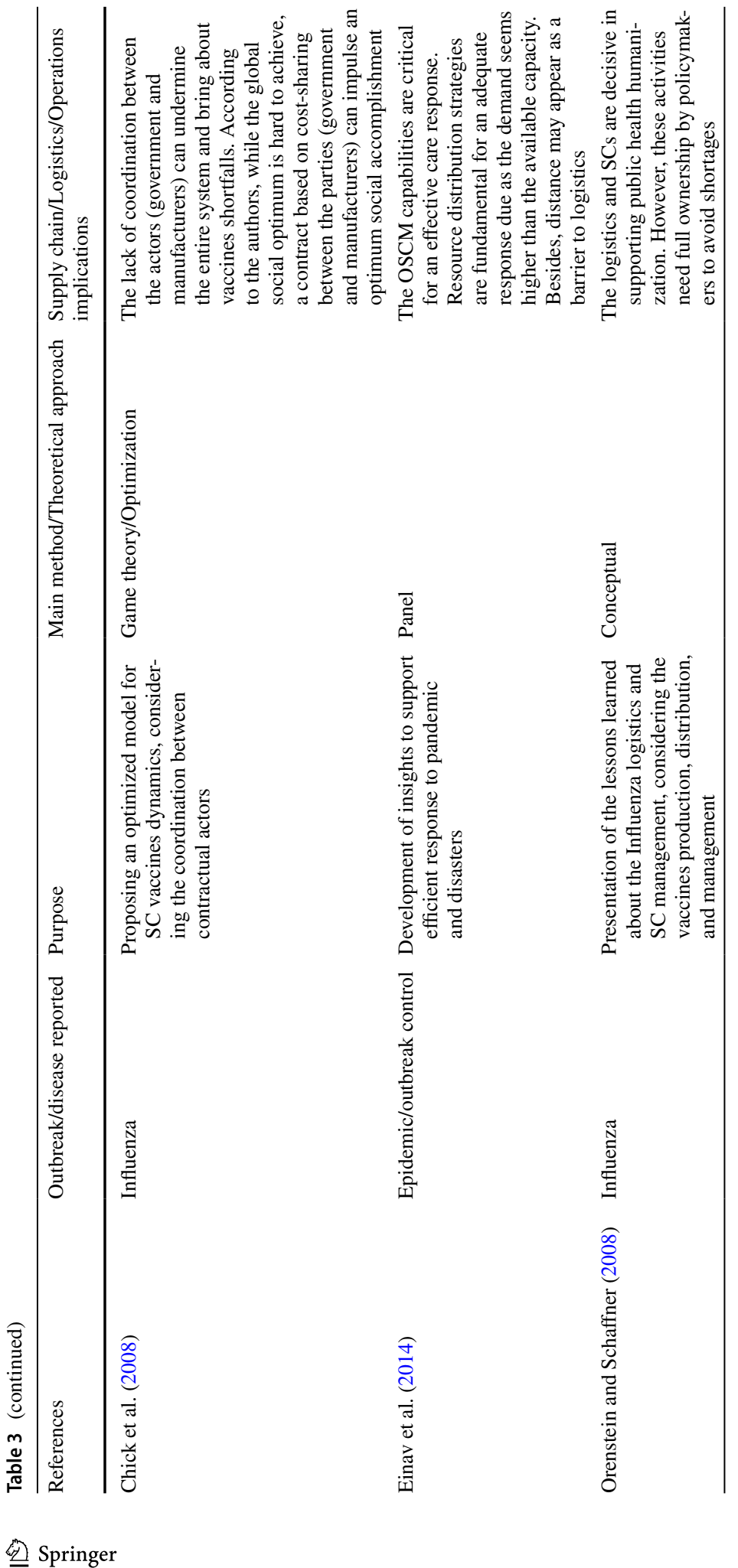




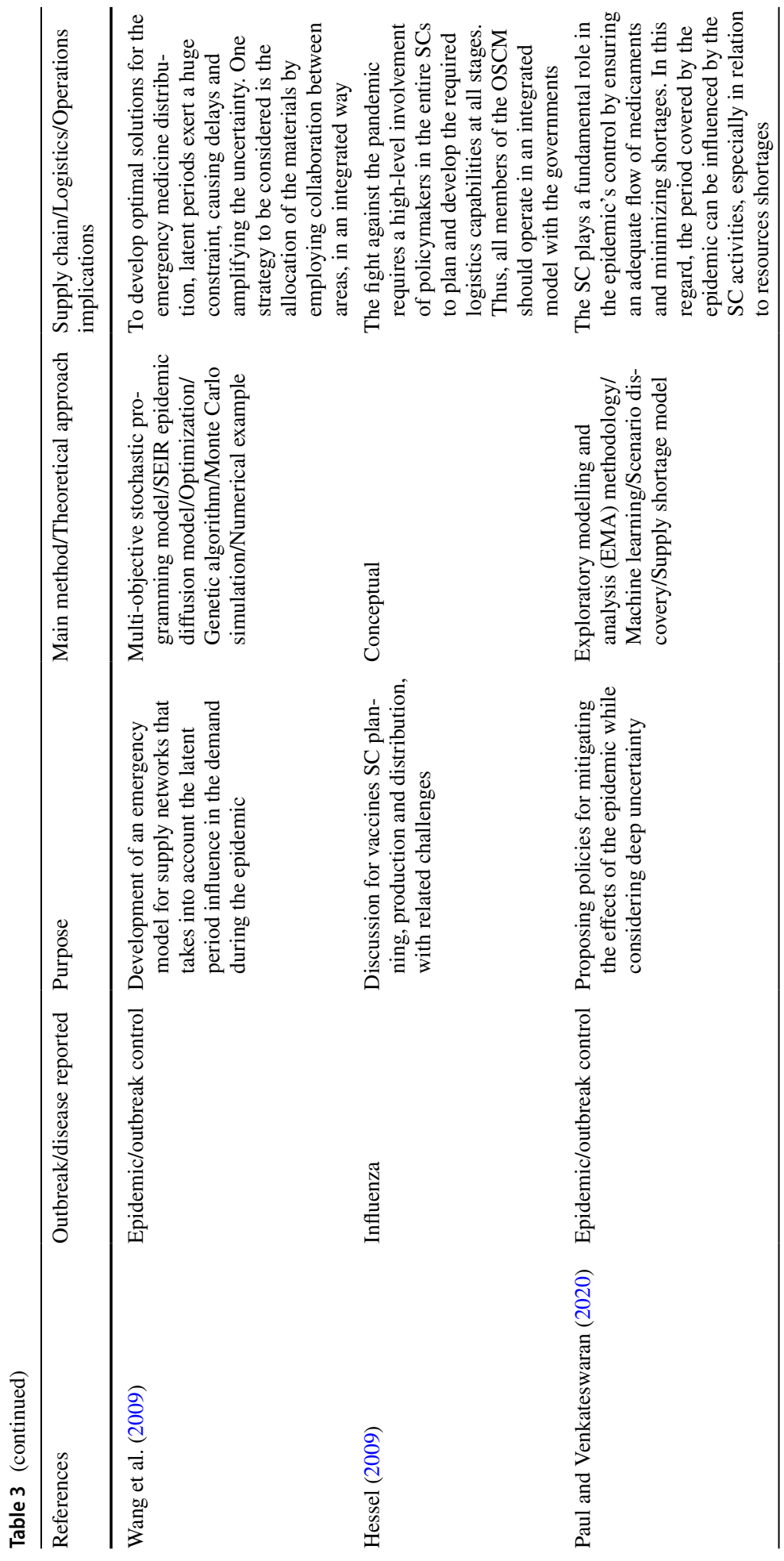




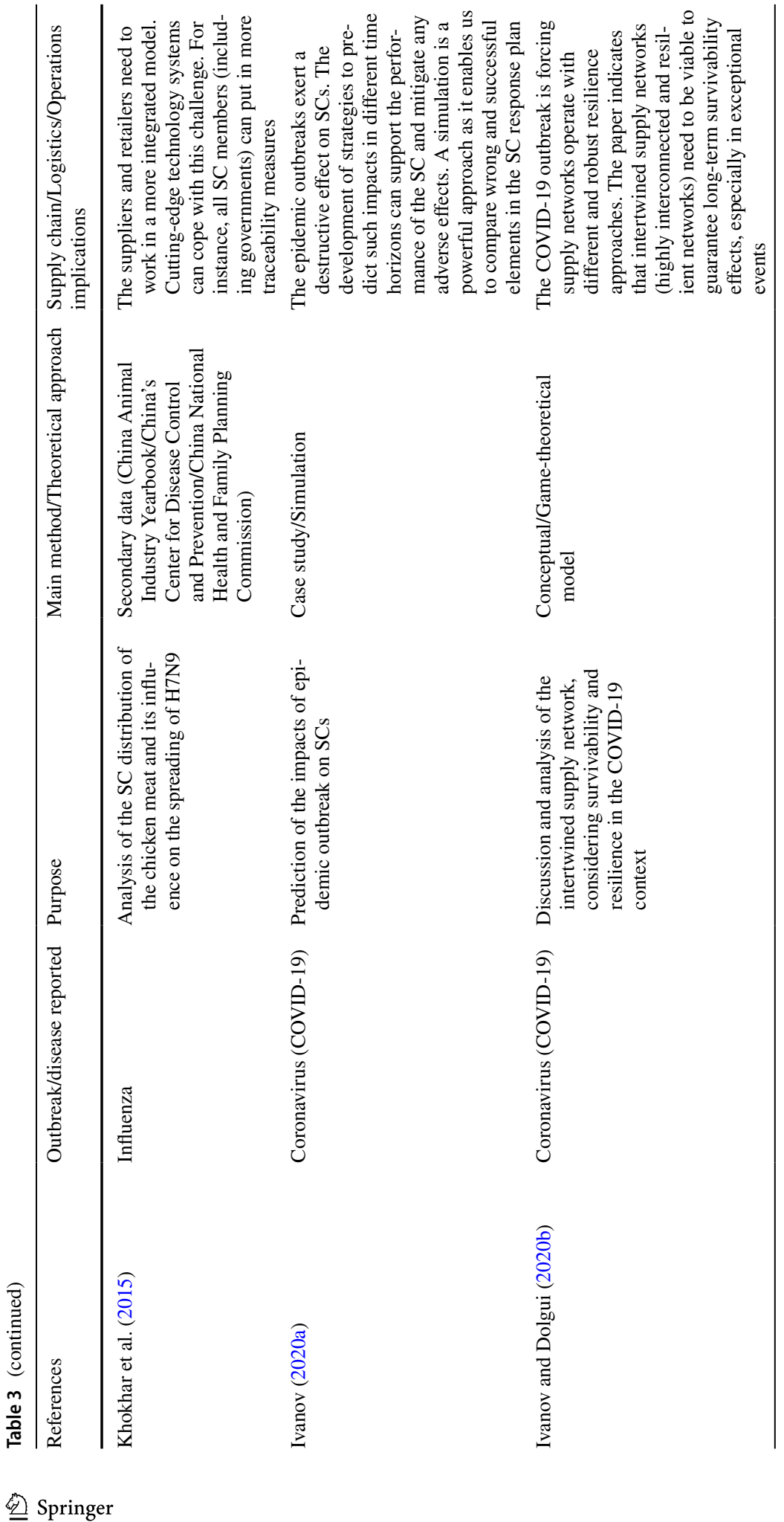




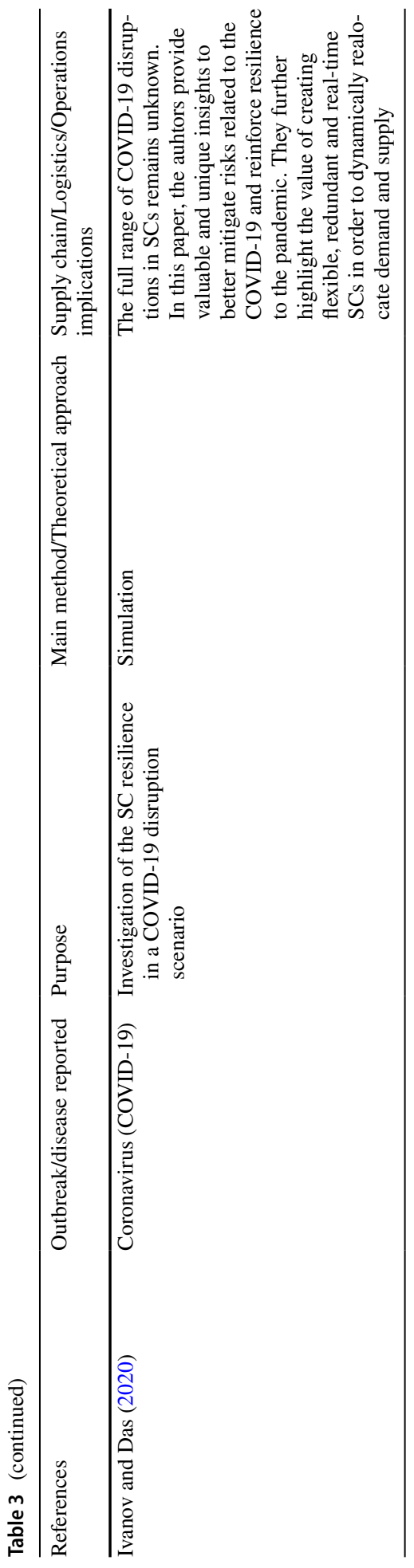


Table 4 Analysis of papers by a content analysis approach

\begin{tabular}{lcc}
\hline Epidemic/outbreak reported & $\begin{array}{l}\text { Number of } \\
\text { papers }\end{array}$ & Percentage \\
\hline Influenza & 14 & 43.75 \\
Epidemic/outbreak control & 6 & 18.75 \\
Cholera & 4 & 12.50 \\
Ebola & 3 & 9.38 \\
Coronavirus (COVID-19) & 3 & 9.38 \\
Malaria & 1 & 3.13 \\
Smallpox & 1 & 3.13 \\
Total & 32 & 100.00 \\
\hline
\end{tabular}

Lastly, concerning the "Supply chain/Logistics/Operations implications", several interesting points were raised. For example, resource management is a great preoccupation (Rachaniotis et al. 2012; Savachkin and Uribe 2012; Long et al. 2018). In this regard, it should be noted that logistics and SCs play an essential role in coordinating and integrating the multiple members' activities (Mamani et al. 2013), including manufacturers, transportation, hospitals, government, etc. Moreover, in a recent study, Paul and Venkateswaran (2020) emphasized the impact of the SC in order to control epidemic outbreaks. The authors pointed out that the SCs should provide an adequate flow of medicaments and other products to avoid materials shortage. Thus, SCs can influence the duration of an epidemic outbreak.

Recent studies by Govindan et al. (2020) and Ivanov (2020a) also presented the devasting impact of the COVID-19/SARS-CoV-2 on global SCs. This does not mean that interesting and new findings on the impact of COVID-19 on SCs have not been obtained. For instance, SCM decision-makers are henceforth well equipped to make use of the available technologies and relevant techniques (including simulation) to predict impacts on their organizations/firms' SCs. Besides, analytics techniques to support decision-making in logistics operations (Griffith et al. 2019; Dubey et al. 2019b), and social media analytics to support emergency operations decisions (Fosso Wamba et al. 2019), play an essential role in order to minimize the epidemic impacts on SCs. Moreover, it is well demonstrated that the SC performance response relies on the scale and timing of the disruption spreading and not on the upstream disruption duration. Ivanov (2020a) went on identifying a positive effect of disruptions on SCs responses (upstream and downstream sides) to an epidemic, when the disruption is simultaneous.

\section{Research agenda for operations and supply chain management at the times of COVID-19 pandemic}

This section deals with the main theoretical and managerial implications of our study with the objective to tease out a research agenda for OSCM at the times of COVID-19 pandemic. To start, Table 5 synthesizes open research questions following the identified literature gaps and makes important suggestions to scholars and practitioners.

We organized the literature gaps and open questions in three clusters, namely: the modeling cluster, the organizational cluster, and the technology cluster. The modeling cluster covers optimization, simulation or other OR methods. In the organizational cluster, we 


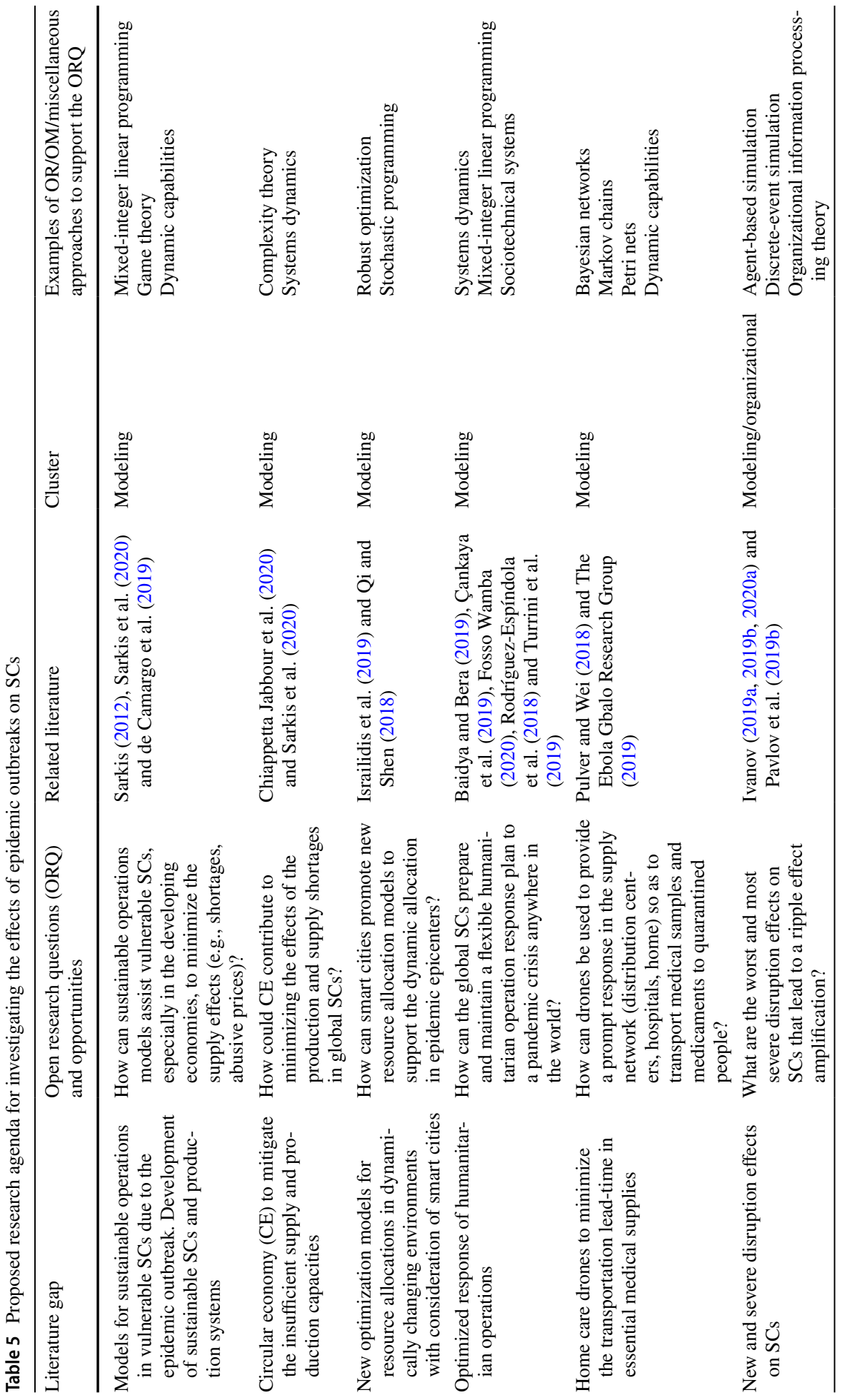




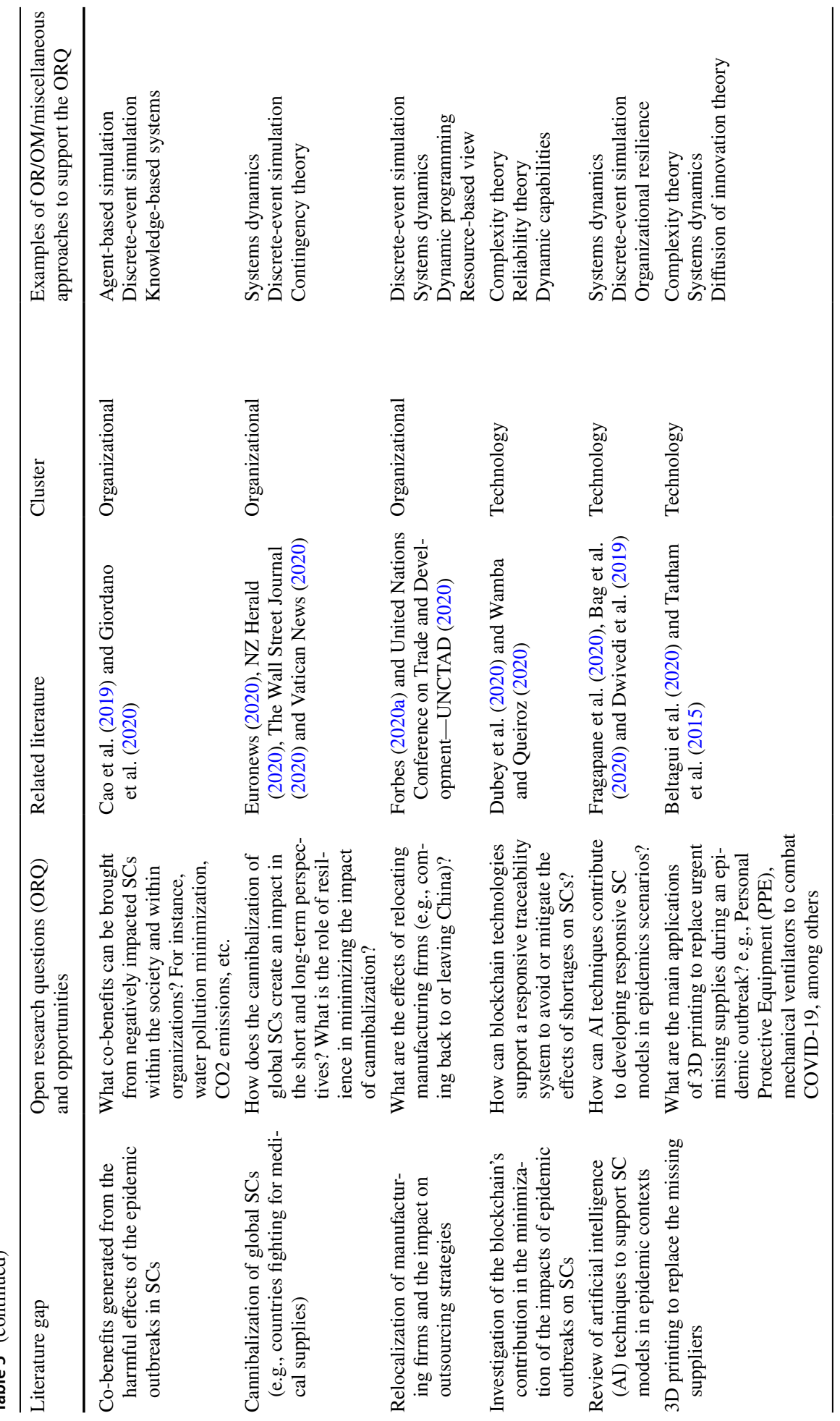


consider different forms of SC organisation, including intertwined supply networks (Ivanov and Dolgui 2020b), to improve collaboration with SCs and their interrelation with the society, etc. For example, the co-benefits generated by epidemic outbreaks are practically unknown, along with the cannibalization of global SCs and the relocalization of manufacturing firms. The technology cluster is dedicated to digital technologies, additive manufacturing, and data analytics. For instance, it addresses the question of how to use disruptive technologies to manage SC disruptions during epidemic crises.

Besides, in the last column of Table 5, we highlighted some suggested and adherent theories of operations $(\mathrm{OR} / \mathrm{OM})$ and miscellaneous theories to support the examination of the challenging open research questions (ORQ). In this vein, we identified from our literature analysis suitable OR/OM approaches such as network and complexity theories (e.g., Bayesian networks, complexity theory, reliability theory, petri nets, and Markov chains), mathematical optimization (e.g., mixed-integer linear programming, stochastic programming, metaheuristics, robust optimization, and dynamic programming), and simulation (e.g., agent-based simulation, discrete-event simulation, and systems dynamics). Moreover, these approaches could be integrated with empirical theories in exploring operations such as dynamic capabilities, absorptive capacity, organizational resilience, sociotechnical systems, organizational information processing theory, knowledge-based systems, contingency theory, resource-based view, and diffusion of innovation theory.

In that context, these theories could bring valuable support in exploring the impact of epidemic outbreaks on SCs. For instance, the mathematical optimization theories can be used develop optimized plan and schedules to avoid shortages, and also deal with ramp-up demands (e.g., toilet paper manufacturers ramping up production due to COVID-19). Simulation techniques allow to develop robust resilience plans, considering new and severe disruptions (e.g., agent-based simulation allows to examines operations behaviours taking into account simultaneous interactions of multiple agents, during and after the COVID-19). Furthermore, due to the complexity of the COVID-19, these approaches could be integrated with some network and complexity theories (e.g., combining some simulation theory with reliability analysis, decision-makers could develop complex scenarios to cope with resource scarcity and simultaneous supply and demand substitutions required at each stage of a pandemic).

In Fig. 4, we summarise the results of our analyses as an emerging research agenda on OSCM under pandemics and epidemic outbreaks.

The research agenda in Fig. 4 is teased out the Tables 3 and 5. It shows open research questions as an extension of our findings during a systematic literature review. Now we discuss the individual components presented in Table 5 and Fig. 4 in detail.

\subsection{Preparedeness focus}

Pre-allocation of resources and emergency distribution planning have been identified in our our SLR as the most visible topics with the preparedeness focus whereas optimization methods dominate this area. In this sense, the research opportunities relate not only to optimization models, but also to the need to implement more sophisticated simulation techniques (Currie et al. 2020). In addition, queuing theory, scheduling and forecasting approaches need to be explored in pandemic contexts. Our study sheds more light on the importance of managing and allocating resources in an adequate 


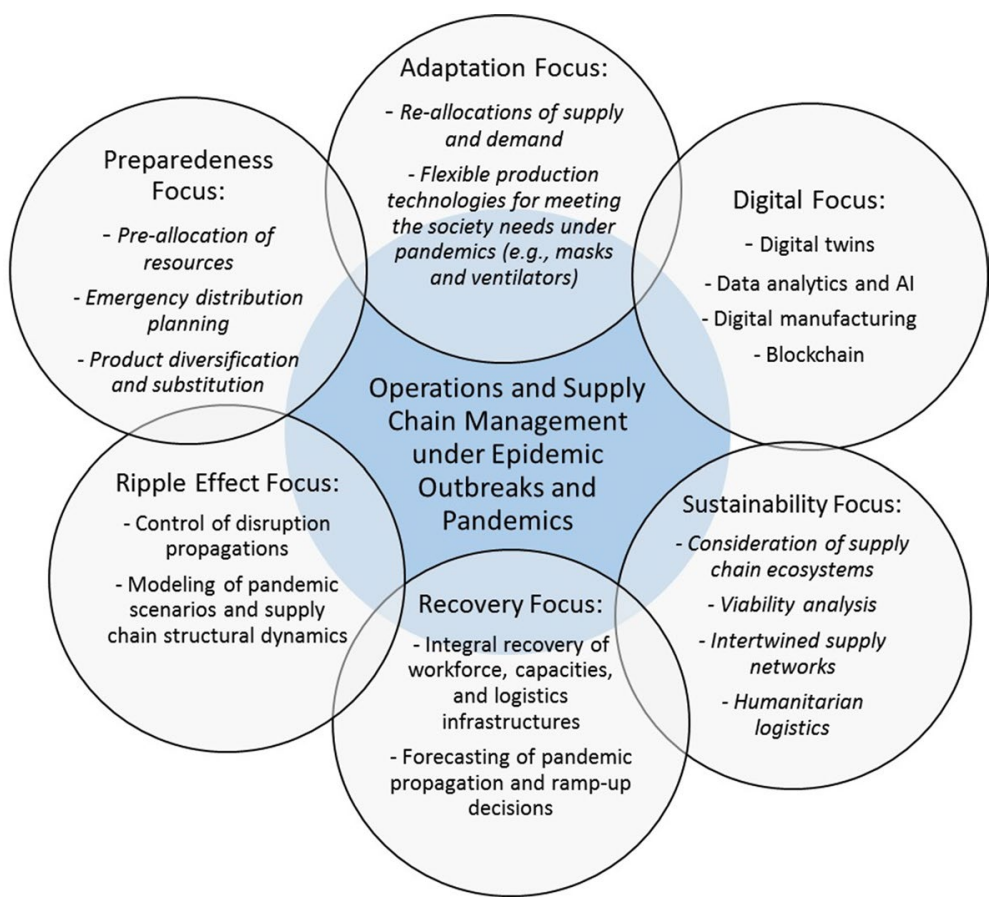

Fig. 4 Emerging research agenda on OSCM under pandemics and epidemic outbreaks

way (Pavlov et al. 2019a). This means that decision-makers and policy-makers should improve their organizations' SC resilience and response capacity by employing not only optimization techniques but also simulations (Paul et al. 2019). First, an indepth understanding of status quo in SC responsiveness and resilience can be achieved through simulations (Currie et al. 2020; Ivanov 2020a; Ivanov and Das 2020). Second, simulation is essential to predict massive disruption scenarios and the required performance capacities.

\subsection{Digital focus}

Questions related to cutting-edge technologies like blockchain and AI techniques, for improved response traceability, are fundamental to provide robust, resilient SC models. On the other hand, there is an urgent need to explore the 3D printing/additive manufacturing to efficient and timely deployment of medical equipment. Moreover, the first analyses of COVID-19 pandemic impacts on SCs and production systems suggest that Industry 4.0 and digital manufacturing can play a critical role for SC resilience and ripple effect control (Ivanov and Dolgui 2019; Hosseini et al. 2019). In terms of visibility and digital control, the firms that are successful in digital manufacturing networks seem to be better positioned in crisis times and in the coordination of future recovery processes (Choi et al. 2020; Dubey et al. 2019a; Ivanov et al. 2019; Panetto et al. 2019; Ivanov 2020a, b; Ivanov and Dolgui 2020a, b; Ivanov and Das 2020; Ni 2020). 


\subsection{Adaptation and recovery focus}

We found several tensions related to SC responses to past disruptions caused by epidemic outbreaks. From the theoretical perspective, we found that the OSCM literature has addressed the past disruptions caused by the epidemic outbreaks by employing mainly optimization approaches, especially in relation to resources allocation (Büyüktahtakın et al. 2018; Liu and Zhang 2016; Parvin et al. 2018; Rachaniotis et al. 2012). Managers and practitioners need to continuously monitor SCs, as no stage of epidemics' impacts should be left unturned before any recovery plan is properly implemented and managed. To this end, one of the main lessons from the extant literature is that the OSCM field exerts a great influence on the duration of epidemics (Paul and Venkateswaran 2020). Therefore, the OSCM should operate from the resilience perspective (Dubey et al. 2019c; Dolgui et al. 2020), avoiding medicament and equipment shortages, providing a dynamic and responsive operation model at the different stages of the outbreak. In addition, recent studies on the disruptions of SCs provoked by epidemic outbreaks showed that simulation is an important technique to predict and develop plans to respond to such impacts on OSCM (Currie et al. 2020; Ivanov 2020a; Ivanov and Das 2020; Ivanov and Dolgui 2020b).

\subsection{Ripple effect focus}

Our next finding is that epidemic outbreaks could significantly impact the SCs triggering a highly and unexplored ripple effect (Ivanov 2020a). The main important theoretical implication resides in reinforcing the need to deepen the understanding of the simultaneous deployment of the ripple effects and epidemic outbreaks on SCs (Ivanov and Das 2020; Ivanov and Dolgui 2020b). The ripple effect is a very strong stressor to SCs and their ongoing collapses amid pandemic coming from the disruption propagations through the networks. Adversely, the situation is stimulated by simultaneous disruptions and uncertainties in demand and supply. The existing knowledge in modelling the SC ripple effect (Dolgui et al. 2018) is multi-faceted and deserves to be analysed for the unique set of factors shaping SC adaptations during and after a global pandemic.

\subsection{Sustainability focus}

The sustainability focus builds around consideration of SC ecosystems and viability. An SC can be considered viable if it is able to maintain itself and an ecosystem balance (i.e., achieve homeostasis) (Ivanov and Dolgui 2020b). Sarkis et al. (2020) point to the potentials of the circular economy to ensure long-term SC survivability. Moreover, there are multiple feedback cycles in the SC ecosystems, including both positive and negative feedbacks. As pointed in Ivanov (2020b), the interactions of the SC and nature are concerned with a positive cycle of using natural resources and a negative cycle of emissions as potential contributors to climate change. The interaction with society results in positive feedbacks such as technological innovations and workforce development although negative feedbacks in terms of possible labor strikes (disruptions at SC resilience level) or global pandemics (disruptions at SC survivability level) also exist. In this vein, the 
analysis can be brought to the levels of intertwined supply networks (ISN), i.e., "the entirety of interconnected supply chains which, in their integrity secure the provision of society and markets with goods and services" (Ivanov and Dolgui 2020b). Finally, the issues of humanitarian logistics and SCs build a central perspective in the sustainability focus (Besiou and van Wassenhove 2020; Dubey et al. 2020; Fosso Wamba 2020). From this perspective, additional research is essential to address concerns of process improvement in humanitarian operations (Larson and Foropon 2018).

\subsection{A discussion note on SC resilience at the pandemic times}

Based on our findings, we propose a classification of relevant aspects of SC resilience, in view of the particularities of some epidemic outbreaks and global pandemics. The results of our analysis show that the traditional SC risk and resilience understanding (Tang 2006; Govindan et al. 2017; Chen et al. 2019; Dolgui et al. 2018; Ivanov et al. 2018; DuHadway et al. 2019) is restrictive in tackling long-term, global pandemic disruptions. Therefore, we call for new approaches (Ivanov 2020a; Ivanov and Das 2020; Ivanov and Dolgui 2020b) or for the extension of the existing ones. Based on the categorization proposed by Ivanov and Dolgui (2019), we therefore propose to categorize the SC resilience actions in the context of pandemic disruptions, using four main categories, namely: systems, process, control, and recovery, as reported in Table 6.

A set of critical components of SC resilience can be selected for each category. Besides, it should be noted that all the categories coming into play in the epidemic outbreak are interralated and correlated (e.g., preparedness, response, recovery). As such, faced with important disruptions caused by epidemics, SCs need to reinforce their resilience, including throught increased SC viability (Ivanov and Dolgui 2020b).

The available systems are considered a critical aspect of resilience performance by the literature (Aven 2017; Ivanov and Dolgui 2019). They encompass physical and digital components when it comes to SCs (Queiroz et al. 2019a), and support the various interactions of the epidemic outbreak.

The process category is focused on the interplay between flexibility and product management (Dolgui and Proth 2010; Ivanov and Dolgui 2019), as acknowledged by the relevant literature. This category calls for a detailed network for the flow of products while avoiding shortages. One efficient strategy for coping with these is related to the process redundancy (Ivanov and Dolgui 2019).

The control theory is a well-established conceptualization scheme that has been successfully used in the area of SC disruption and resilience (Ivanov et al. 2016, 2017; Spiegler et al. 2016). Severe epidemic outbreaks, including the COVID-19, fall in this category

Table 6 Categorization for SC resilience to epidemic outbreaks

\begin{tabular}{ll}
\hline Category & Components \\
\hline Systems & Structures, resources, capacities, interactions (responses, coordination) \\
Process & Distribution, transportation, procurement, production, resources allocation, flexibility \\
Control & $\begin{array}{c}\text { Inventory control, sourcing control, manufacturing control, resilience as KPI in optimization } \\
\text { models }\end{array}$ \\
Recovery & $\begin{array}{c}\text { Manufacturing production, human labor, transportation network, suppliers, production flex- } \\
\text { ibility }\end{array}$ \\
\hline
\end{tabular}


and are amplified, more than ever, by the complexities of the system's dynamics. Consequently, new control policies to inventory, sourcing and manufacturing, coupled with the resilience of the KPI's in optimization models, are required.

The recovery stage plays a fundamental role in SC resilience (Ivanov and Dolgui 2019; Elluru et al. 2019). It includes different policies for network reconfiguration (Ivanov et al. 2016), with the engagement and interaction of internal and external resources (e.g., manufacturing production, human labor, transportation network, suppliers, and production flexibility). It should be noted that because of shortages (human labor, products) and restrictions on the transportation network (World Economic Forum-WEF 2020a), recovering from disruptions caused by the pandemic vary according to regional policies and may face some delays. The recovery process could be accelerated by relying on alternative sources, along with the adoption of production flexibility strategies (World Economic ForumWEF 2020a). For instance, by streamlining their production systems, manufacturing firms could produce more medical supplies to shorten the impacts of epidemics on SCs (World Economic Forum-WEF 2020a).

\section{Conclusion}

The coronavirus (COVID-19) outbreak shows that pandemics and epidemics can seriously wreak havoc on supply chains (SC) around the globe. In this study, we presented a systematic analysis of the impacts of epidemic outbreaks on SCs guided by a structured literature review that collated a unique set of publications on epidemic outbreak impacts on SCs. Utilizing the outcomes of our analysis, we tease out a series of open research questions that would not be observed otherwise.

In terms of findings and contributions, this study showed that the interplay between SCs and epidemic outbreaks has so far traditionally focused on resource allocation problems and supply medicals distribution, using optimization approaches and epidemic models (Büyüktahtakın et al. 2018; Mamani et al. 2013; Rachaniotis et al. 2012). It has also revealed that such an interplay has been dominated by the influenza epidemic, though other relevant epidemic outbreaks are being reported in the SC context.

In this respect, the COVID-19 pandemic is already devastating global SCs. It should be recalled that investigating the impacts of epidemic outbreaks on SCs is a new but robust research stream (Ivanov 2020a). This study ended up providing an insightful and challenging research agenda to scholars and practitioners interested in exploring more deeply the effects of epidemic outbreaks on SCs. In this vein, we identified robust literature gaps and open question opportunities, which we classified in three clusters (modeling, technology, and organizational).

Most centrally, we proposed a framework of OSCM at the times of COVID-19 pandemic that spans six perspectives, i.e., adaptation, digitalization, preparedness, recovery, ripple effect, and sustainability. Despite the development of novel classifications and categorizations as well as articulation of novel theoretical tensions, our study harbors a number of limitations. The query used to search the keywords on the databases could be a barrier in exploring other SC-related themes. In the future, additional studies could adopt and extend our protocol for much better results. In addition, this work has been limited by the scarcity of research about the effects of epidemic outbreaks on SCs. Only 32 documents were found to fully meet our research protocol. Furthermore, as the COVID-19 effects on SCs are still going on and look increasingly devastating, there is not much room for comparative 
analysis. Considering such limitations, especially in the literature gap related to the effects of epidemic outbreaks on SCs, we have proposed research agenda for future studies.

In future, one promising research avenue is to frame the analyses of SC behaviors during and after the pandemic in the vein of viability. Viability nicely integrates resilience, adaptation, and sustainability views the importance of which in the analysis of SCs under pandemic conditions has been noted and reported (Ivanov 2020b; Ivanov and Dolgui 2020b; Sarkis et al. 2020). Another interesting research avenue is to enrich the OSCM methodical variety by the methods from other disciplines; e.g., to investigate the application of SEIR and epidemic diffusion models to the analysis of SC ripple effect or to study the applications of ecological modelling to SC viability. These and other directions open new, at times unforeseen research avenues where the OSCM can make substantial contributions to theory and practice in order to help firms to remain impactful and relevant during and after the COVID-19 pandemic.

Acknowledgements Open Access funding provided by Projekt DEAL. The authors thank Associate Editor and two anonymous reviewers for their invaluable comments which helped to improve this paper immensely.

Open Access This article is licensed under a Creative Commons Attribution 4.0 International License, which permits use, sharing, adaptation, distribution and reproduction in any medium or format, as long as you give appropriate credit to the original author(s) and the source, provide a link to the Creative Commons licence, and indicate if changes were made. The images or other third party material in this article are included in the article's Creative Commons licence, unless indicated otherwise in a credit line to the material. If material is not included in the article's Creative Commons licence and your intended use is not permitted by statutory regulation or exceeds the permitted use, you will need to obtain permission directly from the copyright holder. To view a copy of this licence, visit http://creativecommons.org/licenses/by/4.0/.

\section{References}

Aldrighetti, R., Zennaro, I., Battini, D., \& Finco, S. (2019). Healthcare supply chain simulation with disruption considerations: A case study from Northern Italy. Global Journal of Flexible Systems Management, 20, 81-102. https://doi.org/10.1007/s40171-019-00223-8.

Amiri-Aref, M., Farahani, R. Z., Hewitt, M., \& Klibi, W. (2019). Equitable location of facilities in a region with probabilistic barriers to travel. Transportation Research Part E: Logistics and Transportation Review, 127, 66-85.

Anparasan, A. A., \& Lejeune, M. (2017). Analyzing the response to epidemics: Concept of evidence-based Haddon matrix. Journal of Humanitarian Logistics and Supply Chain Management, 7(3), 266-283. https://doi.org/10.1108/JHLSCM-06-2017-0023.

Anparasan, A. A., \& Lejeune, M. (2019). Resource deployment and donation allocation for epidemic outbreaks. Annals of Operations Research, 283(1-2), 9-32. https://doi.org/10.1007/s10479-016-2392-0.

Anparasan, A. A., \& Lejeune, M. A. (2018). Data laboratory for supply chain response models during epidemic outbreaks. Annals of Operations Research, 270(1-2), 53-64. https://doi.org/10.1007/s10479-017-2462-y.

Aria, M., \& Cuccurullo, C. (2017). bibliometrix : An R-tool for comprehensive science mapping analysis. Journal of Informetrics, 11(4), 959-975. https://doi.org/10.1016/j.joi.2017.08.007.

Aven, T. (2017). How some types of risk assessments can support resilience analysis and management. Reliability Engineering and System Safety, 167, 536-543. https://doi.org/10.1016/j.ress.2017.07.005.

Bag, S., Wood, L. C., Mangla, S. K., \& Luthra, S. (2020). Procurement 4.0 and its implications on business process performance in a circular economy. Resources, Conservation and Recycling, 152, 104502. https://doi.org/10.1016/j.resconrec.2019.104502.

Baidya, A., \& Bera, U. K. (2019). New model for addressing supply chain and transport safety for disaster relief operations. Annals of Operations Research, 283(1-2), 33-69. https://doi.org/10.1007/s1047 9-018-2765-7.

Banomyong, R., Varadejsatitwong, P., \& Oloruntoba, R. (2019). A systematic review of humanitarian operations, humanitarian logistics and humanitarian supply chain performance literature 2005-2016. Annals of Operations Research, 283(1-2), 71-86. https://doi.org/10.1007/s10479-017-2549-5. 
Beltagui, A., Kunz, N., \& Gold, S. (2020). The role of 3D printing and open design on adoption of socially sustainable supply chain innovation. International Journal of Production Economics, 221, 107462. https://doi.org/10.1016/j.ijpe.2019.07.035.

Bernardet, U., Fdili Alaoui, S., Studd, K., Bradley, K., Pasquier, P., \& Schiphorst, T. (2019). Assessing the reliability of the Laban movement analysis system. PLOS ONE, 14(6), e0218179. https://doi. org/10.1371/journal.pone.0218179.

Besiou, M., \& Van Wassenhove, L. N. (2020). Humanitarian operations: A world of opportunity for relevant and impactful research. Manufacturing \& Service Operations Management, 22(1), 135-145.

Boccaletti, S., Ditto, W., Mindlin, G., \& Atangana, A. (2020). Modeling and forecasting of epidemic spreading: The case of Covid-19 and beyond. Chaos, Solitons \& Fractals, 135, 109794. https://doi. org/10.1016/j.chaos.2020.109794.

Bode, C., Wagner, S. M., Petersen, K. J., \& Ellram, L. M. (2011). Understanding responses to supply chain disruptions: Insights from information processing and resource dependence perspectives. Academy of Management Journal, 54(4), 833-856.

Bogoch, I. I., Creatore, M. I., Cetron, M. S., Brownstein, J. S., Pesik, N., Miniota, J., et al. (2015). Assessment of the potential for international dissemination of Ebola virus via commercial air travel during the 2014 west African outbreak. The Lancet, 385(9962), 29-35. https://doi.org/10.1016/S0140-6736(14)61828-6.

Bóta, A., Gardner, L. M., \& Khani, A. (2017). Identifying critical components of a public transit system for outbreak control. Networks and Spatial Economics, 17(4), 1137-1159. https://doi.org/10.1007/s1106 7-017-9361-2.

Brandenburg, M., \& Rebs, T. (2015). Sustainable supply chain management: A modelling perspective. Annals of Operations Research, 229(1), 213-252. https://doi.org/10.1007/s10479-015-1853-1.

Business Insider. (2020). The coronavirus outbreak is disrupting supply chains around the world-Here's how companies can adjust and prepare. Retrieved March 30, 2020, from https://www.businessinsider .com/covid-19-disrupting-global-supply-chains-how-companies-can-react-2020-3.

Büyüktahtakın, E., des-Bordes, E., \& Kıbış, E. Y. (2018). A new epidemics-logistics model: Insights into controlling the Ebola virus disease in West Africa. European Journal of Operational Research, 265(3), 1046-1063. https://doi.org/10.1016/j.ejor.2017.08.037.

Çankaya, E., Ekici, A., \& Özener, O. Ö. (2019). Humanitarian relief supplies distribution: An application of inventory routing problem. Annals of Operations Research, 283(1-2), 119-141. https://doi. org/10.1007/s10479-018-2781-7.

Cao, C., Cui, X. Q., Cai, W., Wang, C., Xing, L., Zhang, N., et al. (2019). Incorporating health co-benefits into regional carbon emission reduction policy making: A case study of China's power sector. Applied Energy, 253, 113498. https://doi.org/10.1016/j.apenergy.2019.113498.

Chen, H. Y., Das, A., \& Ivanov, D. (2019). Building resilience and managing post-disruption supply chain recovery: Lessons from the information and communication technology industry. International Journal of Information Management, 49, 330-342. https://doi.org/10.1016/j.ijinfomgt.2019.06.002.

Chew, D. S. H., Choi, K. P., Heidner, H., \& Leung, M. Y. (2004). Palindromes in SARS and other coronaviruses. INFORMS Journal on Computing, 16(4), 331-340. https://doi.org/10.1287/ijoc.1040.0087.

Chiappetta Jabbour, C. J., Seuring, S., de Lopes de Sousa Jabbour, A. B., Jugend, D., De Camargo Fiorini, P., Latan, H., et al. (2020). Stakeholders, innovative business models for the circular economy and sustainable performance of firms in an emerging economy facing institutional voids. Journal of Environmental Management, 264(February), 110416. https://doi.org/10.1016/j.jenvman.2020.110416.

Chick, S. E., Mamani, H., \& Simchi-Levi, D. (2008). Supply chain coordination and influenza vaccination. Operations Research, 56(6), 1493-1506. https://doi.org/10.1287/opre.1080.0527.

Choi, T.-M. (2020). Innovative "Bring-service-near-your-home" operations under corona-virus (COVID-19/ SARS-CoV-2) outbreak: Can logistics become the messiah? Transportation Research Part E: Logistics and Transportation. (Forthcoming).

Choi, T. Y., Rogers, D., \& Vakil, B. (2020). Coronavirus is a wake-up call for supply chain management. Retrieved March 30, 2020, from https://hbr.org/2020/03/coronavirus-is-a-wake-up-call-for-suppl y-chain-management.

Cochrane Library. (2018). Cochrane database of systematic reviews. Retrieved July 15, 2018, from https:// www.cochranelibrary.com/.

Cruz, M. A., Hawk, N. M., Poulet, C., Rovira, J., \& Rouse, E. N. (2015). Public health incident management: Logistical and operational aspects of the 2009 initial outbreak of H1N1 influenza in Mexico. Journal of Emergency Management, 13(1), 71-77. https://doi.org/10.5055/jem.2015.0219.

Cuccurullo, C., Aria, M., \& Sarto, F. (2016). Foundations and trends in performance management. A 25 years bibliometric analysis in business and public administration domains. Scientometrics, 108(2), 595-611. https://doi.org/10.1007/s11192-016-1948-8. 
Currie, C. S. M., Fowler, J. W., Kotiadis, K., Monks, T., Onggo, B. S., Robertson, D. A., et al. (2020). How simulation modelling can help reduce the impact of COVID-19. Journal of Simulation. https://doi. org/10.1080/17477778.2020.1751570.

Dasaklis, T. K., Pappis, C. P., \& Rachaniotis, N. P. (2012). Epidemics control and logistics operations: A review. International Journal of Production Economics, 139(2), 393-410. https://doi.org/10.1016/j. ijpe.2012.05.023.

Dasaklis, T. K., Rachaniotis, N., \& Pappis, C. (2017). Emergency supply chain management for controlling a smallpox outbreak: The case for regional mass vaccination. International Journal of Systems Science: Operations and Logistics, 4(1), 27-40. https://doi.org/10.1080/23302674.2015.1126379.

de Camargo, J. A., Mendonça, P. S. M., de Oliveira, J. H. C., Jabbour, C. J. C., \& de Sousa Jabbour, A. B. L. (2019). Giving voice to the silent: A framework for understanding stakeholders' participation in socially-oriented initiatives, community-based actions and humanitarian operations projects. Annals of Operations Research, 283(1-2), 143-158. https://doi.org/10.1007/s10479-017-2426-2.

Deloitte. (2020). COVID-19: Managing supply chain risk and disruption. Retrieved March 30, 2020, from https://www2.deloitte.com/global/en/pages/risk/articles/covid-19-managing-supply-chain-risk-anddisruption.html.

Demirel, G., MacCarthy, B. L., Ritterskamp, D., Champneys, A., \& Gross, T. (2019). Identifying dynamical instabilities in supply networks using generalized modeling. Journal of Operations Management, 65(2), 133-159.

Demiroz, F., \& Haase, T. W. (2019). The concept of resilience: A bibliometric analysis of the emergency and disaster management literature. Local Government Studies, 45(3), 308-327. https://doi. org/10.1080/03003930.2018.1541796.

Dolgui, A., Ivanov, D., \& Sokolov, B. (2018). Ripple effect in the supply chain: An analysis and recent literature. International Journal of Production Research, 56(1-2), 414-430. https://doi. org/10.1080/00207543.2017.1387680.

Dolgui, A., Ivanov, D., \& Sokolov, B. (2020). Reconfigurable supply chain: The X-network. International Journal of Production Research. https://doi.org/10.1080/00207543.2020.1774679.

Dolgui, A., \& Proth, J. M. (2010). Supply chain engineering: Useful methods and techniques. London: Springer.

Dubey, R., Altay, N., \& Blome, C. (2019a). Swift trust and commitment: The missing links for humanitarian supply chain coordination? Annals of Operations Research, 283(1-2), 159-177. https://doi. org/10.1007/s10479-017-2676-z.

Dubey, R., Gunasekaran, A., Bryde, D. J., Dwivedi, Y. K., \& Papadopoulos, T. (2020). Blockchain technology for enhancing swift-trust, collaboration and resilience within a humanitarian supply chain setting. International Journal of Production Research. https://doi.org/10.1080/00207 543.2020.1722860.

Dubey, R., Gunasekaran, A., Childe, S. J., Fosso Wamba, S., Roubaud, D., \& Foropon, C. (2019b). Empirical investigation of data analytics capability and organizational flexibility as complements to supply chain resilience. International Journal of Production Research. https://doi. org/10.1080/00207543.2019.1582820.

Dubey, R., Gunasekaran, A., Childe, S. J., Papadopoulos, T., Blome, C., \& Luo, Z. (2019c). Antecedents of resilient supply chains: An empirical study. IEEE Transactions on Engineering Management, 66(1), 8-19. https://doi.org/10.1109/TEM.2017.2723042.

DuHadway, S., Carnovale, S., \& Hazen, B. (2019). Understanding risk management for intentional supply chain disruptions: Risk detection, risk mitigation, and risk recovery. Annals of Operations Research, 283(1-2), 179-198. https://doi.org/10.1007/s10479-017-2452-0.

Dwivedi, Y. K., Hughes, L., Ismagilova, E., Aarts, G., Coombs, C., Crick, T., et al. (2019). Artificial intelligence (AI): Multidisciplinary perspectives on emerging challenges, opportunities, and agenda for research, practice and policy. International Journal of Information Management. https ://doi.org/10.1016/j.ijinfomgt.2019.08.002.

Einav, S., Hick, J. L., Hanfling, D., Erstad, B. L., Toner, E. S., Branson, R. D., et al. (2014). Surge capacity logistics: Care of the critically ill and injured during pandemics and disasters-Chest consensus statement. Chest, 146, e17S-e43S. https://doi.org/10.1378/chest.14-0734.

Ekici, A., Keskinocak, P., \& Swann, J. L. (2014). Modeling influenza pandemic and planning food distribution. Manufacturing and Service Operations Management, 16(1), 11-27. https://doi. org/10.1287/msom.2013.0460.

Elluru, S., Gupta, H., Kaur, H., \& Singh, S. P. (2019). Proactive and reactive models for disaster resilient supply chain. Annals of Operations Research, 283(1-2), 199-224. https://doi.org/10.1007/s1047 9-017-2681-2. 
Enayati, S., \& Özaltın, O. Y. (2020). Optimal influenza vaccine distribution with equity. European Journal of Operational Research, 283(2), 714-725. https://doi.org/10.1016/j.ejor.2019.11.025.

Euronews. (2020). Medical supply shortage spurs global scramble for materials. Retrieved April 5, 2020, from https://www.euronews.com/2020/04/04/medical-supply-shortage-spurs-global-scram ble-for-materials.

Forbes. (2020a). COVID-19 undermines China's run as the world's factory, but Beijing has a plan. Retrieved April 7, 2020, from https:/www.forbes.com/sites/wadeshepard/2020/03/26/covid-19undermines-chinas-run-as-the-worlds-factory-but-beijing-has-a-plan/\#11f640c459a9.

Forbes. (2020b). The coronavirus' impact on the global automotive supply chain. Retrieved March 30, 2020, from https://www.forbes.com/sites/laurieharbour1/2020/03/13/the-coronavirus-impact-onthe-global-automotive-supply-chain/\#2f607021444e.

Fortune. (2020). 94\% of the Fortune 1000 are seeing coronavirus supply chain disruptions: Report. Retrieved March 30, 2020, from https://fortune.com/2020/02/21/fortune-1000-coronavirus-china -supply-chain-impact/.

Fosso Wamba, S. (2020). Humanitarian supply chain: A bibliometric analysis and future research directions. Annals of Operations Research. https://doi.org/10.1007/s10479-020-03594-9.

Fosso Wamba, S., Edwards, A., \& Akter, S. (2019). Social media adoption and use for improved emergency services operations: the case of the NSW SES. Annals of Operations Research, 283(1-2), 225-245. https://doi.org/10.1007/s10479-017-2545-9.

Fragapane, G., Ivanov, D., Peron, M., Sgarbossa, F., \& Strandhagen, J. O. (2020). Increasing flexibility and productivity in Industry 4.0 production networks with autonomous mobile robots and smart intralogistics. Annals of Operations Research. https://doi.org/10.1007/s10479-020-03526-7.

Ghadge, A., Dani, S., Chester, M., \& Kalawsky, R. (2013). A systems thinking approach for modelling supply chain risk propagation. Supply Chain Management: An International Journal, 18(5), 523-538.

Giordano, R., Pluchinotta, I., Pagano, A., Scrieciu, A., \& Nanu, F. (2020). Enhancing nature-based solutions acceptance through stakeholders' engagement in co-benefits identification and trade-offs analysis. Science of the Total Environment. https://doi.org/10.1016/j.scitotenv.2020.136552.

Govindan, K., et al. (2020). A decision support system for demand management in healthcare supply chains considering the epidemic outbreaks: A case study of coronavirus disease 2019 (COVID19). Transportation Research Part E: Logistics and Transportation Review. (Forthcoming).

Govindan, K., Fattahi, M., \& Keyvanshokooh, E. (2017). Supply chain network design under uncertainty: A comprehensive review and future research directions. European Journal of Operational Research, 263(1), 108-141.

Griffith, D. A., Boehmke, B., Bradley, R. V., Hazen, B. T., \& Johnson, A. W. (2019). Embedded analytics: Improving decision support for humanitarian logistics operations. Annals of Operations Research, 283(1-2), 247-265. https://doi.org/10.1007/s10479-017-2607-z.

Haren, P., \& Simchi-Levi, D. (2020). How coronavirus could impact the global supply chain by midMarch. Retrieved March 30, 2020, from https://hbr.org/2020/02/how-coronavirus-could-impac t-the-global-supply-chain-by-mid-march.

Harvard Business Review. (2020). Coronavirus is proving we need more resilient supply chains. Retrieved April 5, 2020, from https://hbr.org/2020/03/coronavirus-is-proving-that-we-need-moreresilient-supply-chains.

Hessel, L. (2009). Pandemic influenza vaccines: Meeting the supply, distribution and deployment challenges. Influenza and Other Respiratory Viruses, 3(4), 165-170. https://doi.org/10.111 1/j.1750-2659.2009.00085.x.

Hosseini, S., \& Ivanov, D. (2019). Resilience assessment of supply networks with disruption propagation considerations: A Bayesian network approach. Annals of Operations Research. https://doi. org/10.1007/s10479-019-03350-8.

Hosseini, S., Ivanov, D., \& Dolgui, A. (2019). Review of quantitative methods for supply chain resilience analysis. Transportation Research Part E, 125, 285-307.

Institute for Supply Chain Management-ISM. (2020). Coronavirus impact on supply chain. Retrieved March 29, 2020, from https://weareism.org/coronavirus-ism.html.

International Journal of Production Research. (2020a). Special issue: Production of healthcare under epidemic outbreaks. Retrieved April 5, 2020, from https://techjournals.wixsite.com/techjournals/ production-healthcare-epidemic.

International Journal of Production Research. (2020b). Special issue: Viability of supply networks and ecosystems-Lessons learned from COVID-19 outbreak. Retrieved April 5, 2020, from https:// techjournals.wixsite.com/techjournals/viability-supply-networks-ecosystem. 
Israilidis, J., Odusanya, K., \& Mazhar, M. U. (2019). Exploring knowledge management perspectives in smart city research: A review and future research agenda. International Journal of Information Management. https://doi.org/10.1016/j.ijinfomgt.2019.07.015.

Ivanov, D. (2019a). 'A blessing in disguise' or 'as if it wasn't hard enough already': Reciprocal and aggravate vulnerabilities in the supply chain. International Journal of Production Research. https ://doi.org/10.1080/00207543.2019.1634850.

Ivanov, D. (2019b). Disruption tails and revival policies: A simulation analysis of supply chain design and production-ordering systems in the recovery and post-disruption periods. Computers and Industrial Engineering, 127, 558-570.

Ivanov, D. (2020a). Predicting the impacts of epidemic outbreaks on global supply chains: A simulationbased analysis on the coronavirus outbreak. Transportation Research Part E, 136(March), 101922. https://doi.org/10.1016/j.tre.2020.101922.

Ivanov, D. (2020b). Viable supply chain model: Integrating agility, resilience and sustainability perspectives. Lessons from and thinking beyond the COVID-19 pandemic. Annals of Operations Research. https://doi.org/10.1007/s10479-020-03640-6.

Ivanov, D., Das, A., \& Choi, T. -M. (2018). New flexibility drivers in manufacturing, service, and supply chain systems. International Journal of Production Research, 56(10), 3359-3368.

Ivanov, D., \& Das, A. (2020). Coronavirus (COVID-19/SARS-CoV-2) and supply chain resilience: A research note. International Journal of Integrated Supply Management, 58(10), 2904-2915.

Ivanov, D., \& Dolgui, A. (2019). Low-certainty-need (LCN) supply chains: A new perspective in managing disruption risks and resilience. International Journal of Production Research, 57(15-16), 5119-5136. https://doi.org/10.1080/00207543.2018.1521025.

Ivanov, D., \& Dolgui, A. (2020a). A digital supply chain twin for managing the disruptions risks and resilience in the era of Industry 4.0. Production Planning and Control. https://doi.org/10.1080/09537 287.2020.1768450.

Ivanov, D., \& Dolgui, A. (2020b). Viability of intertwined supply networks: Extending the supply chain resilience angles towards survivability. A position paper motivated by COVID-19 outbreak. International Journal of Production Research, 58(10), 2904-2915.

Ivanov, D., Dolgui, A., \& Sokolov, B. (2019). The impact of digital technology and Industry 4.0 on the ripple effect and supply chain risk analytics. International Journal of Production Research, 57(3), 829-846. https://doi.org/10.1080/00207543.2018.1488086.

Ivanov, D., Pavlov, A., Dolgui, A., Pavlov, D., \& Sokolov, B. (2016). Disruption-driven supply chain (re)planning and performance impact assessment with consideration of pro-active and recovery policies. Transportation Research Part E: Logistics and Transportation Review, 90, 7-24. https://doi. org/10.1016/j.tre.2015.12.007.

Ivanov, D., Pavlov, A., Pavlov, D., \& Sokolov, B. (2017). Minimization of disruption-related return flows in the supply chain. International Journal of Production Economics, 183, 503-513. https://doi. org/10.1016/j.ijpe.2016.03.012.

Ivanov, D., \& Sokolov, B. (2019). Simultaneous structural-operational control of supply chain dynamics and resilience. Annals of Operations Research, 283(1-2), 1191-1210. https://doi.org/10.1007/s1047 9-019-03231-0.

Johns Hopkins University \& Medicine. (2020). Coronavirus COVID-19 global cases by the center for systems science and engineering (CSSE). Retrieved April 22, 2020, from https://coronavirus.jhu.edu/map.html.

Journal of Operations Management. (2020). Special issue of the Journal of Operations ManagementThe effects of COVID-19 on global supply chains: responsiveness, resilience, and restoration (3Rs). Retrieved April 5, 2020, from https://onlinelibrary.wiley.com/pb-assets/assets/18731317/JOMCF P-COVID-19andglobalsupplychains-1585601180383.pdf.

Kache, F., \& Seuring, S. (2014). Linking collaboration and integration to risk and performance in supply chains via a review of literature reviews. Supply Chain Management: An International Journal, 19(5/6), 664-682. https://doi.org/10.1108/SCM-12-2013-0478.

Khokhar, S. G., Min, Q., \& Su, C. (2015). Bird flu (H7N9) outbreak and its implications on the supply chain of poultry meat in China. Journal of Applied Poultry Research, 24(2), 215-221. https://doi. org/10.3382/japr/pfv007.

Larson, P. D., \& Foropon, C. (2018). Process improvement in humanitarian operations: An organisational theory perspective. International Journal of Production Research, 56(21), 6828-6841. https://doi. org/10.1080/00207543.2018.1424374.

Li, Y., \& Zobel, C. W. (2020). Exploring supply Chain network resilience in the presence of the ripple effect. International Journal of Production Economics. https://doi.org/10.1016/j.ijpe.2020.107693. 
Lin, Q., Zhao, S., Gao, D., Lou, Y., Yang, S., Musa, S. S., et al. (2020). A conceptual model for the coronavirus disease 2019 (COVID-19) outbreak in Wuhan, China with individual reaction and governmental action. International Journal of Infectious Diseases, 93, 211-216. https://doi.org/10.1016/j. ijid.2020.02.058.

Liu, M., Xu, X., Cao, J., \& Zhang, D. (2019). Integrated planning for public health emergencies: A modified model for controlling H1N1 pandemic. Journal of the Operational Research Society. https://doi. org/10.1080/01605682.2019.1582589.

Liu, M., \& Zhang, D. (2016). A dynamic logistics model for medical resources allocation in an epidemic control with demand forecast updating. Journal of the Operational Research Society, 67(6), 841-852. https://doi.org/10.1057/jors.2015.105.

Long, E. F., Nohdurft, E., \& Spinler, S. (2018). Spatial resource allocation for emerging epidemics: A comparison of greedy, myopic, and dynamic policies. Manufacturing and Service Operations Management, 20(2), 181-198. https://doi.org/10.1287/msom.2017.0681.

Lu, Q., Goh, M., \& De Souza, R. (2017). An empirical investigation of swift trust in humanitarian logistics operations. The Palgrave Handbook of Humanitarian Logistics and Supply Chain Management. https ://doi.org/10.1057/978-1-137-59099-2_9.

Majić, Z., Jukić, I., \& Pavlin, S. (2009). Air transport and logistics in pandemic outbreak of influenza A (H1N1) virus. Promet-Traffic \& Traffico, 21(6), 425-434. https://doi.org/10.7307/ptt.v21i6.258.

Mamani, H., Chick, S. E., \& Simchi-Levi, D. (2013). A game-theoretic model of international influenza vaccination coordination. Management Science, 59(7), 1650-1670. https://doi.org/10.1287/mnsc.1120.1661.

McKinsey \& Company. (2020). Coronavirus and technology supply chains: How to restart and rebuild. Retrieved April 5, 2020, from https://www.mckinsey.com/business-functions/operations/our-insig hts/Coronavirus-and-technology-supply-chains-How-to-restart-and-rebuild?cid = other-eml-alt-mipmck\&hlkid = 1100d1a33fec400eaddddb25a2144b77\&hctky=9984960\&hdpid=584c1e34-bc36-4cf49bc5-cfa736b619.

Muggy, L., \& Heier Stamm, J. L. (2020). Decentralized beneficiary behavior in humanitarian supply chains: Models, performance bounds, and coordination mechanisms. Annals of Operations Research, 284(1), 333-365. https://doi.org/10.1007/s10479-019-03246-7.

Mustafa Kamal, M., \& Irani, Z. (2014). Analysing supply chain integration through a systematic literature review: A normative perspective. Supply Chain Management: An International Journal. https://doi. org/10.1108/SCM-12-2013-0491.

Ni, J. (2020). How China can rebuild global supply chain resilience after COVID-19. Retrieved April 4, 2020, from https://www.weforum.org/agenda/2020/03/coronavirus-and-global-supply-chains/.

Nigmatulina, K. R., \& Larson, R. C. (2009). Living with influenza: Impacts of government imposed and voluntarily selected interventions. European Journal of Operational Research, 195(2), 613-627. https ://doi.org/10.1016/j.ejor.2008.02.016.

NZ Herald. (2020). Covid 19 coronavirus: Countries compete for masks, medical supplies amid global pandemic. Retrieved April 5, 2020, from https://www.nzherald.co.nz/world/news/article.cfm?c_ $\mathrm{id}=2 \&$ objectid $=12322431$.

Orenstein, W. A., \& Schaffner, W. (2008). Lessons learned: Role of influenza vaccine production, distribution, supply, and demand-What it means for the provider. American Journal of Medicine, 121(7 Suppl. 2), S22-S27. https://doi.org/10.1016/j.amjmed.2008.05.004.

Panetto, H., Iung, B., Ivanov, D., Weichhart, G., \& Wang, X. (2019). Challenges for the cyber-physical manufacturing enterprises of the future. Annual Reviews in Control, 47, 200-213.

Parvin, H., Beygi, S., Helm, J. E., Larson, P. S., \& Van Oyen, M. P. (2018). Distribution of medication considering information, transshipment, and clustering: Malaria in Malawi. Production and Operations Management, 27(4), 774-797. https://doi.org/10.1111/poms.12826.

Paul, S., \& Venkateswaran, J. (2020). Designing robust policies under deep uncertainty for mitigating epidemics. Computers \& Industrial Engineering, 140(October 2019), 106221. https://doi.org/10.1016/j. cie.2019.106221.

Paul, S. K., Sarker, R., Essam, D., \& Lee, P. T. W. (2019). A mathematical modelling approach for managing sudden disturbances in a three-tier manufacturing supply chain. Annals of Operations Research, 280, 299-335. https://doi.org/10.1007/s10479-019-03251-w.

Pavlov, A., Ivanov, D., Pavlov, D., \& Slinko, A. (2019a). Optimization of network redundancy and contingency planning in sustainable and resilient supply chain resource management under conditions of structural dynamics. Annals of Operations Research. https://doi.org/10.1007/s10479-019-03182-6.

Pavlov, A., Ivanov, D., Werner, F., Dolgui, A., \& Sokolov, B. (2019b). Integrated detection of disruption scenarios, the ripple effect dispersal and recovery paths in supply chains. Annals of Operations Research. https://doi.org/10.1007/s10479-019-03454-1. 
Petticrew, M. (2001). Systematic reviews from astronomy to zoology: Myths and misconceptions. British Medical Journal, 322(7278), 98-101. https://doi.org/10.1136/bmj.322.7278.98.

Pournader, M., Kach, A., \& Talluri, S. (2020). A review of the existing and emerging topics in supply chain risk management literature. Decision Sciences. https://doi.org/10.1111/deci.12470.

Pulver, A., \& Wei, R. (2018). Optimizing the spatial location of medical drones. Applied Geography, 90, 9-16. https://doi.org/10.1016/j.apgeog.2017.11.009.

Purba, N. P., Handyman, D. I. W., Pribadi, T. D., Syakti, A. D., Pranowo, W. S., Harvey, A., et al. (2019). Marine debris in Indonesia: A review of research and status. Marine Pollution Bulletin, 146, 134144. https://doi.org/10.1016/j.marpolbul.2019.05.057.

Qi, W., \& Shen, Z.-J. M. (2018). A smart-city scope of operations management. SSRN Electronic Journal. https://doi.org/10.2139/ssrn.3177496.

Queiroz, M. M., Pereira, S. C. P., Telles, R., \& Machado, M. C. (2019a). Industry 4.0 and digital supply chain capabilities. Benchmarking: An International Journal. https://doi.org/10.1108/BIJ-12-2018-0435.

Queiroz, M. M., Telles, R., \& Bonilla, S. H. (2019b). Blockchain and supply chain management integration: A systematic review of the literature. Supply Chain Management: An International Journal. https:// doi.org/10.1108/SCM-03-2018-0143.

Rachaniotis, N. P., Dasaklis, T. K., \& Pappis, C. P. (2012). A deterministic resource scheduling model in epidemic control: A case study. European Journal of Operational Research, 216(1), 225-231. https:// doi.org/10.1016/j.ejor.2011.07.009.

Roberta Pereira, C., Christopher, M., \& Lago Da Silva, A. (2014). Achieving supply chain resilience: The role of procurement. Supply Chain Management: An International Journal, 19(5/6), 626-642. https:// doi.org/10.1108/SCM-09-2013-0346.

Rodríguez-Espíndola, O., Albores, P., \& Brewster, C. (2018). Decision-making and operations in disasters: Challenges and opportunities. International Journal of Operations and Production Management, 38(10), 1964-1986. https://doi.org/10.1108/IJOPM-03-2017-0151.

Sarkis, J. (2012). Models for compassionate operations. International Journal of Production Economics, 139, 359-365. https://doi.org/10.1016/j.ijpe.2012.06.018.

Sarkis, J., Cohen, M. J., Dewick, P., \& Schr, P. (2020). A brave new world: lessons from the COVID19 pandemic for transitioning to sustainable supply and production. Resources, Conservation and Recycling. https://doi.org/10.1016/j.resconrec.2020.104894.

Savachkin, A., \& Uribe, A. (2012). Dynamic redistribution of mitigation resources during influenza pandemics. Socio-Economic Planning Sciences, 46(1), 33-45. https://doi.org/10.1016/j. seps.2011.05.001.

Sawik, T. (2019). Two-period versus multi-period model for supply chain disruption management. International Journal of Production Research, 57(14), 4502-4518.

Schanes, K., Dobernig, K., \& Gözet, B. (2018). Food waste matters-A systematic review of household food waste practices and their policy implications. Journal of Cleaner Production, 182, 978-991. https://doi.org/10.1016/j.jclepro.2018.02.030.

Shamsi, N. G., Ali Torabi, S., \& Shakouri, G. H. (2018). An option contract for vaccine procurement using the SIR epidemic model. European Journal of Operational Research, 267(3), 1122-1140. https://doi.org/10.1016/j.ejor.2017.12.013.

Shen, B., \& Li, Q. (2017). Market disruptions in supply chains: A review of operational models. International Transactions in Operational Research, 24, 697-711.

Song, J. M., Chen, W., \& Lei, L. (2018). Supply chain flexibility and operations optimisation under demand uncertainty: A case in disaster relief. International Journal of Production Research, 56(10), 3699-3713.

Spens, K. M., \& Kovács, G. (2006). A content analysis of research approaches in logistics research. International Journal of Physical Distribution \& Logistics Management, 36(5), 374-390. https:// doi.org/10.1108/09600030610676259.

Spiegler, V. L. M., Potter, A. T., Naim, M. M., \& Towill, D. R. (2016). The value of nonlinear control theory in investigating the underlying dynamics and resilience of a grocery supply chain. International Journal of Production Research, 54(1), 265-286. https://doi.org/10.1080/00207 543.2015.1076945.

Sun, L., Depuy, G. W., \& Evans, G. W. (2014). Multi-objective optimization models for patient allocation during a pandemic influenza outbreak. Computers \& Operations Research, 51, 350-359. https ://doi.org/10.1016/j.cor.2013.12.001.

Tachizawa, E. M., \& Wong, C. Y. (2014). Towards a theory of multi-tier sustainable supply chains: A systematic literature review. Supply Chain Management: An International Journal, 19(5/6), 643663. https://doi.org/10.1108/SCM-02-2014-0070. 
Tang, C. S. (2006). Perspectives in supply chain risk management. International Journal of Production Economics, 103(2), 451-488.

Tao, Y., Shea, K., \& Ferrari, M. (2018). Logistical constraints lead to an intermediate optimum in outbreak response vaccination. PLoS Computational Biology, 14(5), 1-20. https://doi.org/10.1371/ journal.pcbi.1006161.

Tatham, P., Loy, J., \& Peretti, U. (2015). Three dimensional printing - a key tool for the humanitarian logistician? Journal of Humanitarian Logistics and Supply Chain Management, 5(2), 188-208.

The Ebola Gbalo Research Group. (2019). Responding to the Ebola virus disease outbreak in DR Congo: When will we learn from Sierra Leone? The Lancet, 393(10191), 2647-2650. https://doi. org/10.1016/S0140-6736(19)31211-5.

The Wall Street Journal. (2020). 3M, under attack from White House, pushes back. Retrieved April 5, 2020, from https://www.wsj.com/articles/3m-under-attack-from-white-house-pushes-back-11585922687.

Tranfield, D., Denyer, D., \& Smart, P. (2003). Towards a methodology for developing evidence-informed management knowledge. British Journal of Management, 14(3), 207-222.

Turrini, L., Besiou, M., Papies, D., \& Meissner, J. (2019). The role of operational expenditures and misalignments in fundraising for international humanitarian aid. Journal of Operations Management. https://doi.org/10.1002/joom.1072.

United Nations Conference on Trade and Development-UNCTAD. (2020). Global trade impact of the coronavirus (COVID-19) epidemic. Retrieved April 8, 2020, from https://unctad.org/en/Publicatio nsLibrary/ditcinf2020d1.pdf.

Vatican News. (2020). Countries fight over medical supplies amid Covid-19 pandemic. Retrieved April 5, 2020, from https://www.vaticannews.va/en/world/news/2020-04/europe-united-states-covid-19medical-supplies.html.

Wamba, S. F., \& Queiroz, M. M. (2020). Blockchain in the operations and supply chain management: Benefits, challenges and future research opportunities. International Journal of Information Management, 52, 102064. https://doi.org/10.1016/j.ijinfomgt.2019.102064.

Wang, H., Wang, X., \& Zeng, A. Z. (2009). Optimal material distribution decisions based on epidemic diffusion rule and stochastic latent period for emergency rescue. International Journal of Mathematics in Operational Research, 1(1-2), 76-96. https://doi.org/10.1504/IJMOR.2009.022876.

World Economic Forum-WEF. (2020a). How China can rebuild global supply chain resilience after COVID-19. Retrieved April 5, 2020, from https://www.weforum.org/agenda/2020/03/coronaviru s-and-global-supply-chains/.

World Economic Forum-WEF. (2020b). What past disruptions can teach us about reviving supply chains after COVID-19. Retrieved March 30, 2020, from https://www.weforum.org/agenda/2020/03/covid -19-coronavirus-lessons-past-supply-chain-disruptions/.

World Health Organization-WHO. (2020). WHO Director-General's opening remarks at the media briefing on COVID-19-11 March 2020. Retrieved March 29, 2020, from https://www.who.int/dg/speec hes/detail/who-director-general-s-opening-remarks-at-the-media-briefing-on-covid-19_11-march -2020 .

Yoon, J., Talluri, S., Yildiz, H., \& Ho, W. (2018). Models for supplier selection and risk mitigation: A holistic approach. International Journal of Production Research, 56(10), 3636-3661.

Zhao, K., Zuo, Z., \& Blackhurst, J. V. (2019). Modelling supply chain adaptation for disruptions: An empirically grounded complex adaptive systems approach. Journal of Operations Management, 65(2), 190-212.

Zhou, B. B., Wu, J., \& Anderies, J. M. (2019). Sustainable landscapes and landscape sustainability: A tale of two concepts. Landscape and Urban Planning, 189, 274-284. https://doi.org/10.1016/j.landurbpla n.2019.05.005.

Publisher's Note Springer Nature remains neutral with regard to jurisdictional claims in published maps and institutional affiliations. 


\section{Affiliations}

\section{Maciel M. Queiroz ${ }^{1}$ (D) Dmitry Ivanov ${ }^{2}$ (D) $\cdot$ Alexandre Dolgui $^{3}$ (D) Samuel Fosso Wamba ${ }^{4}$ (D)}

Maciel M. Queiroz

maciel.queiroz@docente.unip.br

Alexandre Dolgui

alexandre.dolgui@imt-atlantique.fr

Samuel Fosso Wamba

s.fosso-wamba@tbs-education.fr

1 Postgraduate Program in Business Administration, Paulista University - UNIP, São Paulo 04026-002, Brazil

2 Supply Chain and Operations Management, Berlin School of Economics and Law, 10825 Berlin, Germany

3 IMT Atlantique, LS2N - CNRS, La Chantrerie, 4 rue Alfred Kastler, 44307 Nantes, France

4 Information, Operations and Management Sciences, TBS Business School, 1 Place Alphonse Jourdain, 31068 Toulouse, France 